\title{
Uncertainty assessment of current size-resolved parameterizations for below-cloud particle scavenging by rain
}

\author{
X. Wang ${ }^{1}$, L. Zhang ${ }^{2}$, and M. D. Moran ${ }^{2}$ \\ ${ }^{1}$ Kellys Environmental Services, Toronto, Canada \\ ${ }^{2}$ Air Quality Research Division, Science and Technology Branch, Environment Canada, 4905 Dufferin Street, Toronto, \\ Ontario, M3H 5T4, Canada
}

Received: 10 November 2009 - Published in Atmos. Chem. Phys. Discuss.: 2 February 2010

Revised: 6 June 2010 - Accepted: 14 June 2010 - Published: 29 June 2010

\begin{abstract}
Current theoretical and empirical size-resolved parameterizations of the scavenging coefficient $(\Lambda)$, a parameter commonly used in aerosol transport models to describe below-cloud particle scavenging by rain, have been reviewed in detail and compared with available field and laboratory measurements. Use of different formulations for raindropparticle collection efficiency can cause uncertainties in sizeresolved $\Lambda$ values of one to two orders of magnitude for particles in the 0.01-3 $\mu \mathrm{m}$ diameter range. Use of different formulations of raindrop number size distribution can cause $\Lambda$ values to vary by a factor of 3 to 5 for all particle sizes. The uncertainty in $\Lambda$ caused by the use of different droplet terminal velocity formulations is generally small than a factor of 2. The combined uncertainty due to the use of different formulations of raindrop-particle collection efficiency, raindrop size spectrum, and raindrop terminal velocity in the current theoretical framework is not sufficient to explain the one to two order of magnitude under-prediction of $\Lambda$ for the theoretical calculations relative to the majority of field measurements. These large discrepancies are likely caused by additional known physical processes (i.e, turbulent transport and mixing, cloud and aerosol microphysics) that influence field data but that are not considered in current theoretical $\Lambda$ parameterizations. The predicted size-resolved particle concentrations using different theoretical $\Lambda$ parameterization can differ by up to a factor of 2 for particles smaller than $0.01 \mu \mathrm{m}$ and by a factor of $>10$ for particles larger than $3 \mu \mathrm{m}$ after $2-5 \mathrm{~mm}$ of rain. The predicted bulk mass and number concentrations (integrated over the particle size distribution) can differ by a factor of 2 between theoretical and empirical $\Lambda$ parameterizations after $2-5 \mathrm{~mm}$ of moderate intensity rainfall.
\end{abstract}

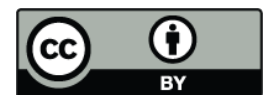

Correspondence to: L. Zhang (leiming.zhang@ec.gc.ca)

\section{Introduction}

Precipitation scavenging of atmospheric aerosol particles is an important removal process that should be included in atmospheric chemical transport models (CTMs) that simulate aerosol particle number and/or mass concentrations. A parameter known as the scavenging coefficient $(\Lambda)$ has been used in the aerosol mass continuity equation in those models to represent below-cloud particle scavenging (Seinfeld and Pandis, 2006). Earlier CTMs only dealt with bulk aerosol mass without the complexity of size-resolved number and mass concentrations (Baklanov, 1999; Rasch et al., 2000; and Jacobson, 2003, and references therein). In these models, $\Lambda$ for bulk mass was commonly parameterized as a function of rainfall intensity (e.g., $\Lambda=A R^{B}$, where $R$ is rainfall intensity and $A$ and $B$ are empirical constants) (Balkanski et al., 1993; Mircea et al., 2000; Baklanov and Sorensen, 2001; Andronache, 2003). Recently developed atmospheric aerosol CTMs, on the other hand, explicitly consider sizeresolved aerosol number and mass concentrations, where $\Lambda$ is expressed as a function of the particle size (e.g., Gong et al., 2003; Loosmore and Cederwall, 2004; Henzing et al., 2006, Tost et al., 2006; Croft et al., 2009). Model intercomparisons have shown that both bulk and size-resolved precipitation scavenging parameterizations have large uncertainties (Rasch et al., 2000; Textor et al., 2006).

Both theoretical and empirical size-resolved $\Lambda$ parameterizations exist in the literature. In the theoretical $\Lambda$ parameterizations, three component parameterizations are needed for raindrop-particle collection efficiency, raindrop number size distribution, and raindrop terminal fall velocity. In the past few decades, a significant number of theoretical and experimental studies have been carried out to investigate $\Lambda$ and these related components (see reviews in Zhang and Vet, 2006; Sportisse, 2007). A number of different analytical, empirical, or semi-empirical formulas have also been developed

Published by Copernicus Publications on behalf of the European Geosciences Union. 
to describe these scavenging components. However, due to the natural variability of raindrop populations and the complexity of microphysical collection processes between particles and raindrops, there has not been any community agreement or consensus as to which formula should be used for the above-mentioned components needed in the calculation of $\Lambda$. For example, the raindrop-particle collection efficiency can be obtained by solving the Navier-Stokes equation for the air flow around a water drop. It is, however, difficult to obtain a theoretical solution of the Navier-Stokes equation for the collision efficiency because of the complicated flow field around the falling drops (e.g., Pruppacher and Klett, 1997). Various collection mechanisms have thus proposed to be included in the calculation of the total collection efficiency (see detailed discussion in Sect. 2.1). There also exist various forms of raindrop number size distribution functions (e.g., exponential, gamma, and lognormal distributions as described in Sect. 2.2) and formulations for raindrop terminal velocity (Sect. 2.3). Different choices have been made by different modelling groups but no systematic uncertainty assessment has been done on the sensitivity of $\Lambda$ to the choice of these input parameters. As for empirically-derived formulas (e.g., Laakso et al., 2003), while these formulas fit the data set from which they were derived well, they might not fit other data sets very well. Therefore, a systematic investigation of the uncertainties in the current theoretical and empirical-derived size-resolved $\Lambda$ parameterizations is needed in order to improve atmospheric aerosol CTMs.

In the present study, theoretical and empirical sizeresolved $\Lambda$ parameterizations are reviewed, compared, and evaluated in a common framework using available measurements. Bulk $\Lambda$ formulas will not be discussed here. In Section 2 , the theory underpinning the theoretical $\Lambda$ parameterizations is briefly described. Section 3 then discusses the uncertainties in the theoretical $\Lambda$ parameterizations caused by the use of different forms of the three component parameterizations: raindrop-particle collection efficiency; raindrop number size distribution; and raindrop terminal fall velocity. In Section 4, both theoretical and empirical size-resolved $\Lambda$ parameterizations are evaluated against available measurements. Section 5 provides examples of the impacts of different theoretical and empirical $\Lambda$ parameterizations on predicted bulk and size-resolved aerosol number and mass concentrations after a short period of precipitation. Lastly, Section 6 closes the paper with further discussions and conclusions.

\section{Theory of below-cloud precipitation scavenging of particles}

The time-dependent removal of aerosol particles by precipitation is commonly described in CTMs as (Seinfeld and Pandis, 2006)

$$
\frac{\partial n(t)}{\partial t}=-\Lambda \cdot n(t)
$$

where $n(t)$ is the particle number concentration at time $t$ and the scavenging coefficient $\Lambda$ has units of inverse time. For CTMs that treat size-resolved aerosol particles, $\Lambda$ should also be a function of particle size. The size-resolved $\Lambda$ is parameterized as

$\Lambda\left(d_{p}\right)=$

$\int_{0}^{\infty} \frac{\pi}{4}\left(D_{p}+d_{p}\right)^{2}\left(V\left(D_{p}\right)-v\left(d_{p}\right)\right) E\left(d_{p}, D_{p}\right) N\left(D_{p}\right) d D_{p}$,

where $d_{p}$ and $D_{p}$ denote particle and raindrop diameters, respectively, $N\left(D_{p}\right)$ is the raindrop number size distribution or size spectrum, and $V\left(D_{p}\right)$ and $v\left(d_{p}\right)$ are the terminal velocities of raindrop and aerosol particles, respectively. $E\left(d_{p}, D_{p}\right)$ is the raindrop-particle collection efficiency, a dimensionless parameter that is defined as the ratio of the total number of collisions occurring between a raindrop and particles to the total number of particles in an area equal to the raindrop's effective cross-sectional area (Slinn, 1983; Pruppacher and Klett, 1997; Seinfeld and Pandis, 2006). Usually the collection efficiency is assumed to be equal with the collision efficiency (Slinn, 1983); that is, the collision between a particle and a raindrop is assumed to result in perfect sticking (the sticking efficiency is unity). This assumption seems reasonable for $d_{p} / D_{p} \ll 1$ (Pruppacher and Klett, 1997). Equation (2) shows that the main factors affecting size-resolved $\Lambda$ include raindrop-particle collection efficiency, raindrop number size distribution, and raindrop terminal velocity. A discussion about how these factors can be determined follows.

\subsection{Raindrop-particle collection efficiency $E\left(d_{p}, D_{p}\right)$}

The raindrop-particle collection efficiency $E\left(d_{p}, D_{p}\right)$ has been investigated extensively in a series of previous studies (e.g., Wang and Pruppacher, 1977; Grover and Pruppacher, 1985; Slinn, 1983; Pruppacher and Klett, 1997; Pinsky and Khain, 2001). Both experimental and theoretical results have shown that $E\left(d_{p}, D_{p}\right)$ is the result of the net action of various forces influencing the relative motion of aerosol particles and hydrometeors. For example, particles following the flow streamlines past a raindrop may be captured by Brownian diffusion or interception. Interception takes place when a particle follows a flow streamline that comes within a distance of one particle radius $\left(d_{p} / 2\right)$ of a droplet. Larger particles tend to experience inertial impaction because of their larger inertia, which prevents them from following the rapidly curving 
streamlines around falling droplets. Interception and inertial impaction are closely related, but interception occurs as a result of particle size neglecting its mass, while inertial impaction is due to particle mass neglecting its size (Seinfeld and Pandis, 2006).

Brownian diffusion, interception, and inertial impaction are believed to be three most important collection mechanisms for below-cloud particle scavenging. However, accurate prediction of the contribution of each collection mechanism to the overall $E\left(d_{p}, D_{p}\right)$ is still very difficult due to the complicated flow patterns around the falling droplet. In practical application, various simplified or empirical formulas for $E\left(d_{p}, D_{p}\right)$ have been induced. Slinn (1983) proposed a formula for $E\left(d_{p}, D_{p}\right)$ by using dimensional analysis coupled with experimental data. Based on Slinn (1983), we use the formula for $E\left(d_{p}, D_{p}\right)$ that is summarized by Seinfeld and Pandis (2006: see Eq. 20.56):

$$
\begin{aligned}
& E\left(d_{p}, D_{p}\right)=\frac{4}{\operatorname{Re} S c}\left[1+0.4 R e^{1 / 2} S c^{1 / 3}+0.16 R e^{1 / 2} S c^{1 / 2}\right] \\
& +4 \frac{d_{p}}{D_{p}}\left[\frac{\mu_{a}}{\mu_{w}}+\left(1+2 R e^{1 / 2}\right) \frac{d_{p}}{D_{p}}\right]+\left(\frac{S t-S t^{*}}{S t-S t^{*}+2 / 3}\right)^{3 / 2},
\end{aligned}
$$

where

$$
\begin{aligned}
& R e=\frac{D_{p} V\left(D_{p}\right) \rho_{a}}{2 \mu_{a}}, \quad S c=\frac{\mu_{a}}{\rho_{a} D_{\mathrm{diff}}}, \quad D_{\mathrm{diff}}=\frac{k_{b} T_{a} C_{c}}{3 \pi \mu_{a} d_{p}}, \\
& S t=\frac{2 \tau\left(V\left(D_{p}\right)-v\left(d_{p}\right)\right)}{D_{p}}, \quad \tau=\frac{\left(\rho_{p}-\rho_{a}\right) d_{p}^{2} C_{c}}{18 \mu_{a}}, \\
& S t^{*}=\frac{1.2+\frac{1}{12} \ln (1+R e)}{1+\ln (1+R e)}, \\
& C_{c}=1+\frac{2 \lambda}{d_{p}}\left(1.257+0.4 \exp \left(-0.55 \frac{d_{p}}{\lambda}\right)\right),
\end{aligned}
$$

and all symbols are defined in Appendix B (Nomenclature).

The first term in Eq. (3) represents Brownian diffusion, the second term represents interception, and the third term represents inertial impaction. Note that the third term is included only when the Stokes number $(S t)$ is greater than the critical Stokes number $\left(S t^{*}\right)$. The third term is also valid as written only for aerosol particles with a density of $1 \mathrm{~g}$ $\mathrm{cm}^{-3}$; otherwise, this term should be scaled by $\left(\rho_{p} / \rho_{w}\right)^{1 / 2}$ (Slinn, 1983; Seinfeld and Pandis, 2006). The above formula for $E\left(d_{p}, D_{p}\right)$ has been widely used in current parameterizations for below-cloud particle scavenging by rain (e.g., Mircea et al., 2000; Chate et al., 2003; Chate, 2005; Andronache, 2003; Andronache et al., 2006; Gong et al., 2003; Loosmore and Cederwall, 2004; Tost et al., 2006; Henzing et al., 2006; Feng, 2007).

Theoretically, Slinn's formula is likely to underestimate $E\left(d_{p}, D_{p}\right)$ since it includes only a subset of the mechanisms that influence particle collection by rain. A number of studies have suggested that thermophoresis, diffusiophoresis, and electric charges may increase $E\left(d_{p}, D_{p}\right)$ for particles in the $0.01-1 \mu \mathrm{m}$ diameter range (e.g., Slinn and Hales, 1971; Grover et al., 1977; Wang et al., 1978; McGann and Jennings, 1991; Byrne and Jennings, 1993; Pranesha and Kamra, 1997; Tripathi and Harrison, 2001; Tinsley et al., 2000; Jaworek et al., 2002; Andronache, 2004; Chate, 2005; Andronache et al., 2006). Thermophoresis, which is caused by uneven heating of particles in ambient temperature gradients, drives particles towards evaporating and sublimating hydrometeors. Diffusiophoresis moves particles towards diffusionally-growing hydrometeors due to water vapour concentration gradients (Chate, 2005). According to Andronache et al. (2006), the thermophoretic and diffusiophoretic contributions to $E\left(d_{p}, D_{p}\right)$ can be expressed, respectively, as follows:

$$
\begin{aligned}
& E_{t h}\left(d_{p}, D_{p}\right)=\frac{4 \alpha_{t h}\left(2+0.6 \operatorname{Re}^{1 / 2} \operatorname{Pr}^{1 / 3}\right)\left(T_{a}-T_{s}\right)}{V\left(D_{p}\right) D_{p}}, \\
& E_{d p h}\left(d_{p}, D_{p}\right)=\frac{4 \beta_{d p h}\left(2+0.6 R e^{1 / 2} S c_{w}^{1 / 3}\right)\left(\frac{P_{s}^{0}}{T_{s}}-\frac{P_{a}^{0} \mathrm{RH}}{T_{a}}\right)}{V\left(D_{p}\right) D_{p}},
\end{aligned}
$$

where

$$
\begin{aligned}
& \alpha_{t h}=\frac{2 C_{c}\left(k_{a}+5 \lambda / D_{p} k_{p}\right) k_{a}}{5 P\left(1+6 \lambda / D_{p}\right)\left(2 k_{a}+k_{p}+10 \lambda / D_{p} k_{p}\right)}, \operatorname{Pr}=\frac{c_{p} \mu_{a}}{k_{a}}, \\
& \beta_{d p h}=\frac{T_{a} D_{\text {diffwater }}}{P} \sqrt{\frac{M_{w}}{M_{a}}} \text {, and } S c_{w}=\frac{\mu_{a}}{\rho_{a} D_{\text {diffwater }}} .
\end{aligned}
$$

The contribution of electric charge to the collection efficiency is based on the concept that a raindrop with a charge $Q_{r}$ attracts an aerosol particle with an opposite charge $q_{p}$ and this process enhances the capture efficiency by the raindrop of aerosol particles close to the raindrop's surface (Andronache, 2004). The electrostatic collection efficiency is expressed as

$E_{e s}\left(d_{p}, D_{p}\right)=\frac{16 K C_{c} Q_{r} q_{p}}{3 \pi \mu_{a} V\left(D_{p}\right) D_{p}^{2} d_{p}}$,

where $K=9 \times 10^{9}$ (in $\mathrm{N} \mathrm{m}^{2} \mathrm{C}^{-2}$ ) and $Q_{r}$ and $q_{p}$ are the mean charges on the raindrop and on the aerosol particle (in Coulomb, C) and are assumed to be of opposite sign. A parameterization with respect to size has been proposed for the mean raindrop and particle charges:

$Q_{r}=a \alpha D_{p}^{2}$, and $q_{p}=a \alpha d_{p}^{2}$,

where $a=0.83 \times 10^{-6}$ and $\alpha\left(\mathrm{C} \mathrm{m}^{-2}\right)$ is an empirical parameter that can vary between 0 , which corresponds to neutral particles, and 7, which corresponds to highly electrified clouds associated with thunderstorms (Andronache, 2004; Andronache et al., 2006). 


\subsection{Raindrop number size distribution $N\left(D_{p}\right)$}

Detailed information about the raindrop number size distribution is essential for understanding the mechanism of below-cloud particle scavenging, estimating the scavenging coefficient $\Lambda$, and improving microphysical parameterizations in numerical weather models and CTMs. Since the pioneering studies of Marshall and Palmer (1948), extensive research has been devoted to modeling the raindrop size distribution (e.g., Ulbrich 1983; Feingold and Levin 1986), and various mathematical functions have been proposed to fit the observed number distributions for raindrops. However, almost no guidance is available to recommend a specific function and its parameters for use in characterizing natural raindrop size spectra because various factors such as rainfall intensity, precipitation type (e.g., stratiform rain, convective rain, thunderstorm), and the stage of rain development all contribute to the formation and evolution of the raindrop size distribution (e.g., Waldvogel, 1974; Sauvageot and Lacaux, 1995; Brandes et al., 2006; Zhang et al., 2008).

At present, the main mathematical functions used to represent the raindrop number size distribution can be divided into three types based on their formulas: exponential distribution; gamma distribution; and lognormal distribution. The exponential distribution is generally written as (e.g., Marshall and Palmer, 1948)

$N\left(D_{p}\right)=N_{0 e} \exp \left(-\beta_{e} D_{p}\right)$,

where $N_{0 e}$ is the intercept parameter and $\beta_{e}$ is a slope parameter. The general form of the gamma distribution can be written as (e.g., Ulbrich, 1983)

$N\left(D_{p}\right)=N_{0 g} D_{p}^{\gamma} \exp \left(-\beta_{g} D_{p}\right)$

Here $N_{0 g}$ is a number concentration parameter, $\gamma$ is a distribution shape parameter, and $\beta_{g}$ is a slope term sensitive to the larger particles. The general form of the lognormal distribution can be written as (e.g., Feingold and Levin, 1986; Cerro et al.,1997)

$N\left(D_{p}\right)=\frac{N_{\text {total }}}{\sqrt{2 \pi} D_{p} \log \sigma_{D}} \exp \left[-\frac{\left(\log D_{p}-\log \bar{D}_{p}\right)^{2}}{2 \log ^{2} \sigma_{D}}\right]$,

where $N_{\text {total }}$ is the total droplet number density, $\bar{D}_{p}$ is the mean droplet diameter, and $\sigma_{D}$ is the droplet-diameter standard deviation. These three parameters of the lognormal function are expressed as functions of rainfall intensity.

In comparison with the exponential distribution, the gamma and lognormal distributions are usually better at representing the characteristics of observed raindrop size distributions at the small-raindrop end (e.g., Ulbrich, 1983; Willis, 1984; Feingold and Levin, 1986; Cerro et al., 1997; Mircea and Stefan, 1998; Mircea et al., 2000; de Wolf, 2001; Bringi et al., 2003; Brandes et al. 2004; Bae et al., 2006; Henzing et al., 2006). This is due to the fact that the exponential function (see Eq. 8) generally includes a fixed intercept parameter $N_{0 e}$ that predicts maximum droplet number concentration for droplet sizes approaching zero. However, many electromechanical disdrometer observations and theoretical studies have shown that the intercept parameter is far from constant and depends systematically on precipitation type, rainfall intensity, and stage of precipitation development (e.g., Waldvogel, 1974; Sauvageot and Lacaux ,1995; Zhang et al., 2008).

These three distribution functions have all been used in the parameterization of size-resolved below-cloud scavenging. Since this type of parameterization considers the full set of interactions between the size spectra of raindrops and aerosol particles, the numerical calculation of $\Lambda$ is very complex and computationally intensive. To reduce the computational burden, some large-scale atmospheric models represent the raindrop size spectrum with a representative raindrop diameter $D_{r}$ (i.e., a monodisperse distribution), generally the median volume diameter (e.g., Gong et al., 2003; Gong et al., 2006; Loosmore and Cederwall, 2004; Tost et al., 2006). Since all raindrops are assumed to have the same diameter $D_{r}$, the integral form of Eq. (2) can then be simplified to

$\Lambda\left(d_{p}\right)=\frac{\pi}{4} D_{r}^{2} V\left(D_{r}\right) E\left(d_{p}, D_{r}\right) N_{\text {total }}$.

As the rainfall intensity $R\left(\right.$ in $\left.\mathrm{mm} \mathrm{s}^{-1}\right)$ can be defined by the formula

$R=\int_{0}^{\infty} \frac{\pi}{6} D_{p}^{3} V\left(D_{p}\right) N\left(D_{p}\right) d D_{p}$

then for a monodisperse raindrop number size spectrum, the rainfall intensity can be written as

$R=\frac{\pi}{6} D_{r}^{3} V\left(D_{r}\right) N_{\text {total }}$.

Combining Eqs. (11) and (13), $\Lambda$ can then be rewritten for a monodisperse raindrop size spectrum as

$\Lambda\left(d_{p}\right)=\frac{3}{2} \frac{E\left(d_{p}, D_{r}\right) R}{D_{r}}$.

\subsection{Raindrop terminal velocity $V\left(D_{p}\right)$}

The terminal fall velocity of a raindrop is another parameter that is included in the formula of the below-cloud scavenging coefficient (see Eq. 2). Two general approaches have been employed to describe raindrop terminal velocity in belowcloud scavenging parameterizations: (1) empirical formulas derived directly from experimental data and (2) physicallybased parameterizations. Table 1 lists some commonly used empirical formulas for the terminal velocity of falling raindrops.

Physically-based formulas usually divide the population of raindrops into several size ranges that correspond to different, physically-distinct flow regimes (e.g., Beard, 1976; 
Table 1. Parameterizations for raindrop terminal velocity (in $\mathrm{cm} \mathrm{s}^{-1}$ ).

\begin{tabular}{ll}
\hline Source & Approximate formula \\
\hline Kessler (1969) & $V\left(D_{p}\right)=1300 D_{p}^{0.5}$ \\
Atlas and Ulbrich (1977) & $V\left(D_{p}\right)=1767 D_{p}^{0.67}$ \\
Willis (1984) & $V\left(D_{p}\right)=4854 D_{p} \exp \left(-1.95 D_{p}\right)$ \\
Best (1950) & $V\left(D_{p}\right)=958\left[1-\exp \left(-\left(\frac{D_{p}}{0.171}\right)^{1.147}\right)\right]$ \\
Atlas et al. (1973) & $V\left(D_{p}\right)=965-1030 \exp \left(-6 D_{p}\right)$ \\
Brandes et al. (2002) & $V\left(D_{p}\right)=-10.21+4932 D_{p}-9551 D_{p}^{2}+7934 D_{p}^{3}-2362 D_{p}^{4}$ \\
\hline
\end{tabular}

Here $D_{p}$ is in centimeters.

Seinfeld and Pandis, 2006; Jacobson, 2005). Different formulas are employed in different ranges. In the present study, we follow the theoretical formula of Beard (1976) for the most calculations. Beard's scheme assigns each raindrop to one of three physically-distinct flow regimes: Stokes's regime $\left(D_{p} \leq 20 \mu \mathrm{m}\right.$ or $\left.R e \leq 0.01\right)$; the transitional regime $\left(20 \mu \mathrm{m} \leq D_{p} \leq 1 \mathrm{~mm}\right.$ or $\left.0.01 \leq R e \leq 300\right)$; and Newton's regime $\left(1 \mathrm{~mm} \leq D_{p} \leq 7 \mathrm{~mm}\right.$ or $\left.300 \leq R e \leq 4000\right)$. For raindrops in Stokes's regime, the Beard scheme explicitly calculates the terminal velocities using Stokes's formula

$V\left(D_{p}\right)=\frac{D_{p}^{2}\left(\rho_{w}-\rho_{a}\right) g C_{c}}{18 \mu_{a}}$,

where $\rho_{a}$ is air density, $\rho_{w}$ is water density, $\mu_{a}$ is air viscosity, $g$ is the gravitational constant, $D_{p}$ is the raindrop diameter, and $C_{c}$ is the Cunningham correction factor. However, for larger raindrops $\left(D_{p} \geq 20 \mu \mathrm{m}\right.$ or $\left.R e \geq 0.01\right)$, the Stokes's formula is no longer valid and there are no explicit expressions for the terminal velocities. In this case, the Beard scheme calculates a Best number, which is based upon the droplet mass and density as well as the gravitational constant and the air viscosity. Then observations are used to derive the Reynolds number from the Best number. Finally, the terminal velocities can be derived using the definition of the Reynolds number. Expressions for the Best number and empirical relations for the Reynolds number in terms of the Best number are given by Beard (1976) and Jacobson (2005).

\section{Sensitivity of theoretical $\Lambda$ parameterizations to different input-parameter formulations}

As described in Sect. 2, there exist a number of different formulas for raindrop-particle collection efficiency, raindrop number size distribution, and raindrop terminal velocity, the three input parameters needed to calculate size-resolved $\Lambda$ (see Eq. 2). This section focuses on investigating the sensitivity of $\Lambda$ to these different input-parameter formulas.

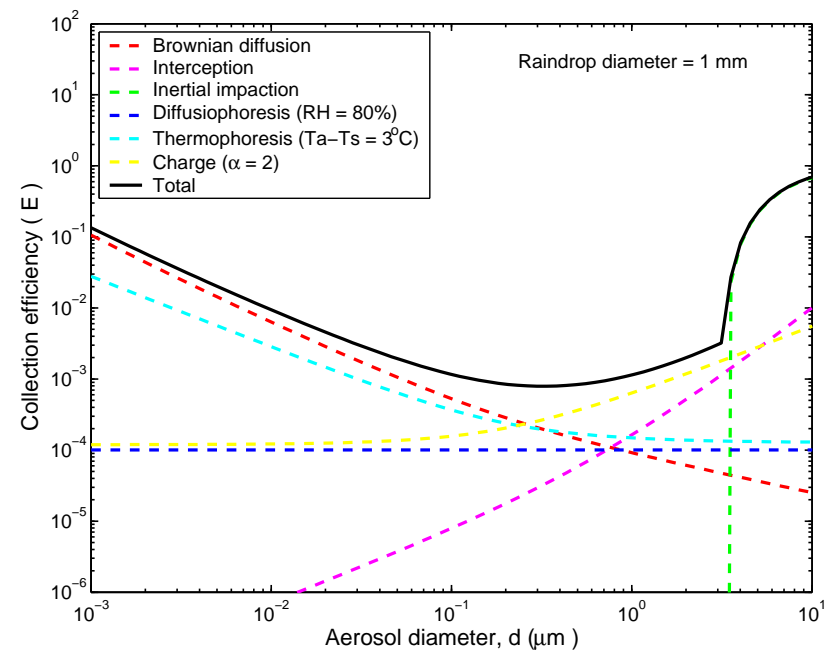

Fig. 1. Contributions of various collection processes to the collection efficiency $E\left(d_{p}, D_{p}\right)$ as a function of the aerosol particle size for a raindrop with diameter of $1 \mathrm{~mm}$.

\subsection{Sensitivity to collection efficiency}

As discussed in Sect. 2.1 the raindrop-particle collection efficiency $E\left(d_{p}, D_{p}\right)$ is controlled by many different microphysical processes. Figure 1 shows the contributions of six microphysical processes to $E\left(d_{p}, D_{p}\right)$ for a wide size range of particles collected by a raindrop $1 \mathrm{~mm}$ in diameter. Calculations are performed based on Eqs. (3) to (6), where (a) raindrop terminal velocities $V\left(D_{p}\right)$ are computed from the theoretical formula of Beard (1976), (b) a $3{ }^{\circ} \mathrm{C}$ temperature difference has been assumed between the raindrop and ambient air to calculate the thermophoretic and diffusiophoretic collection efficiencies (Slinn and Shen, 1970; Slinn and Hales, 1971; and Chate, 2005), and (c) $\alpha=2$ has been assumed for average conditions of electrified clouds to calculate electrostatic collection efficiency (Andronache, 2004).

Clearly, the contribution of Brownian diffusion decreases rapidly as particle size increases. It is the most important 


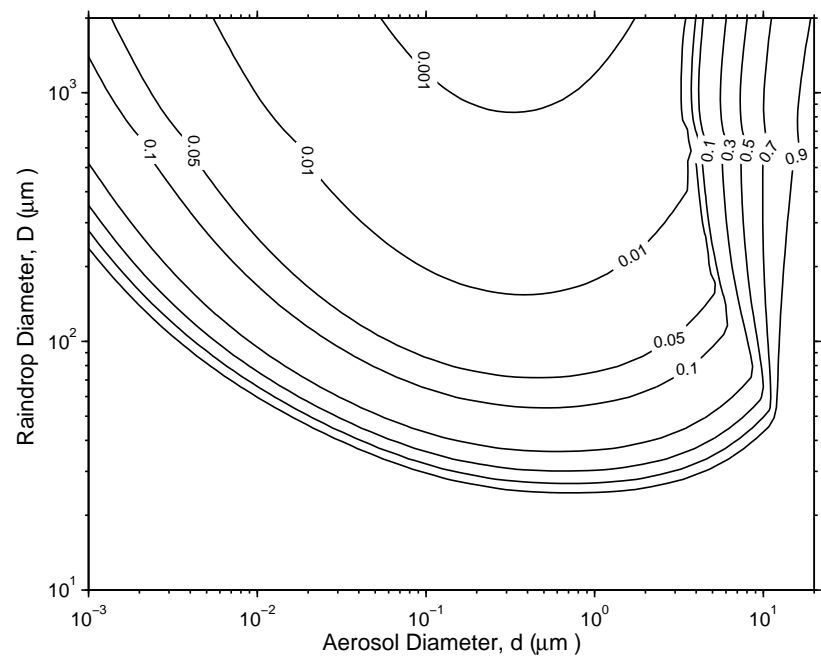

Fig. 2. Total collection efficiency $E\left(d_{p}, D_{p}\right)$ (contoured) taking into account the contributions of all of the processes shown in Fig. 1 as a function of both particle diameter and raindrop diameter.

collection mechanism for smaller particles, particularly ultrafine particles $\left(d_{p}<0.01 \mu \mathrm{m}\right)$, but it contributes little for supermicron particles. Inertial impaction, by contrast, can only occur for particles with a Stokes number $(S t)$ above the critical Stokes number $\left(S t^{*}\right)$, which is close to 1.2 (Phillips and Kaye, 1999; Loosmore and Cederwall, 2004); the corresponding threshold diameter is close to $3 \mu \mathrm{m}$ for unit-density particles and a $1 \mathrm{~mm}$ raindrop. It is worth noting that the influence of particle density on raindrop-particle collection efficiency is very small. This is because the density factor has a squareroot dependence on aerosol density $\left(\left(\rho_{p} / \rho_{w}\right)^{1 / 2}\right)$ and only affects inertial impaction. Figure 1 shows that the contribution of inertial impaction dominates $E\left(d_{p}, D_{p}\right)$ for particles larger than $3.5 \mu \mathrm{m}$. The contribution of interception increases with increasing particle size and appears to be important for particles in the 1 to $3.5 \mu \mathrm{m}$ diameter range. Thermophoresis makes a comparable contribution to Brownian diffusion for particles with $d_{p}$ between 0.1 and $1 \mu \mathrm{m}$. The contribution of diffusiophoresis is smaller than that of thermophoresis for all particle sizes. Finally, the contribution from electric charges increases with particle size and is dominant for particles with $d_{p}$ between 0.3 and $3.5 \mu \mathrm{m}$.

Because of the combined action of the microphysical processes discussed above, total raindrop-particle collection efficiency varies significantly for different particle sizes. Fig. 1 indicates that the collection efficiency is highest for ultrafine particles $\left(d_{p}<0.01 \mu \mathrm{m}\right)$ due to Brownian diffusion and for large particles $\left(d_{p}>3 \mu \mathrm{m}\right)$ due to inertial impaction. However, for particles in the diameter range from 0.01 to $3 \mu \mathrm{m}$, although more of these mechanisms, i.e., Brownian diffusion, interception, diffusiophoresis, thermophoresis and electric charges, play a role in the collection process, the overall magnitude of $E\left(d_{p}, D_{p}\right)$ is very low $\left(<10^{-2}\right)$.

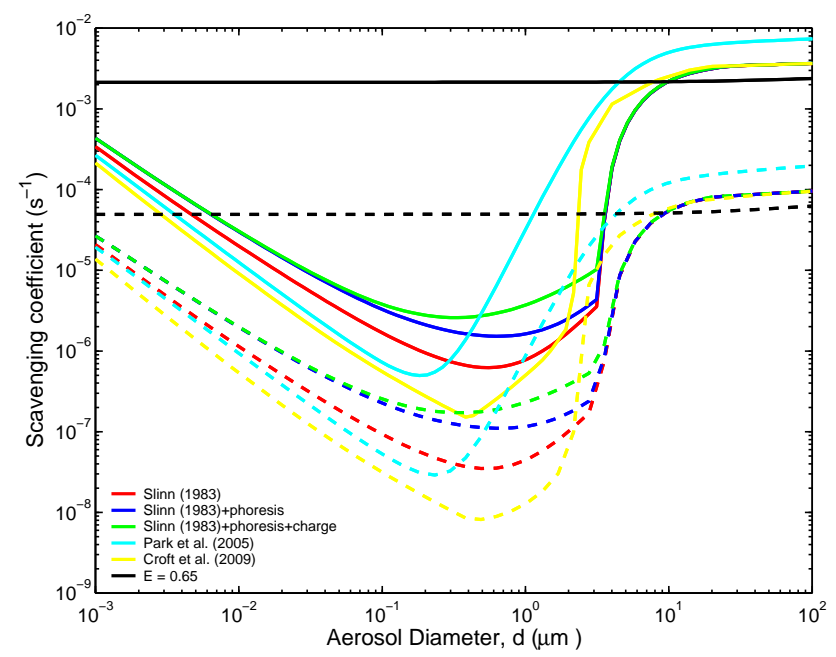

Fig. 3. Scavenging coefficients determined with six different collection efficiency parameterizations as a function of particle size for rainfall intensities of $0.1 \mathrm{~mm} \mathrm{~h}^{-1}$ (dashed line) and $10 \mathrm{~mm} \mathrm{~h}^{-1}$ (solid line).

Figure 2 shows a contour plot of raindrop-particle collection efficiency as a function of both raindrop and particle size calculated using the same conditions as in Fig. 1. It is clear from this figure that the collection efficiency decreases with increasing raindrop size for aerosol particles smaller than $3 \mu \mathrm{m}$ in diameter. The reason is that the dominant collection mechanisms for these particles (i.e., Brownian diffusion for ultrafine particles $\left(d_{p}<0.01 \mu \mathrm{m}\right)$, and Brownian diffusion, interception, thermophoresis, diffusiophoresis, and electric charges for aerosol particles with diameters between 0.01$3 \mu \mathrm{m}$ ) become less efficient as raindrop size increases (see Eqs. 3-6). This can be explained by the larger $V\left(D_{p}\right)$ of the larger particles, which increases $R e$, and thus reduces $E\left(d_{p}, D_{p}\right)$ (see Eq. 3). In contrast, the collection efficiency for large particles $\left(d_{p}>3 \mu \mathrm{m}\right)$ is not very sensitive to raindrop size. This is due to the fact that inertial impaction dominates collection in this size range, and this process has little dependence on raindrop size (see Eq. 3).

Figure 3 shows the sensitivity of the size-resolved scavenging coefficient to different $E\left(d_{p}, D_{p}\right)$ parameterizations for two different rainfall intensities, 0.1 and $10 \mathrm{~mm} \mathrm{~h}^{-1}$, based on calculations using Eq. 2. The raindrop terminal velocity and raindrop size spectrum were parameterized using the Beard scheme and the Marshall-Palmer (MP) distribution, respectively. Figure 3 indicates that the addition of the collection processes of thermophoresis, diffusiophoresis, and electrostatic forces in the Slinn (1983) scheme can increase the predicted $\Lambda$ values by nearly one order of magnificent for particles with diameters between $0.1-3 \mu \mathrm{m}$. For larger particles, these processes have much less effect since inertial impaction dominates over the other mechanisms. 
(a)

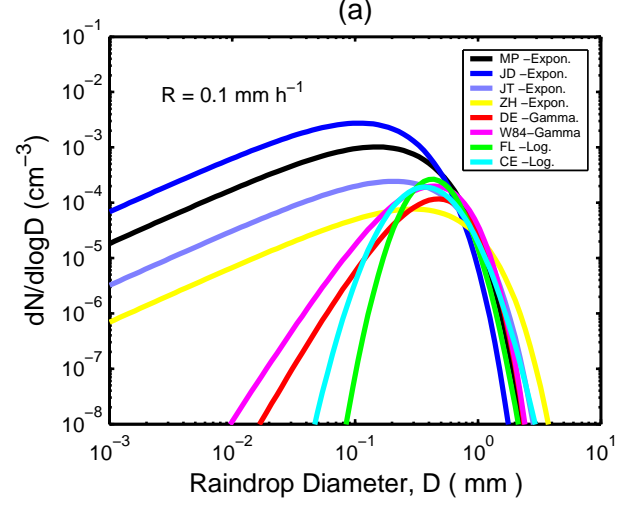

(b)

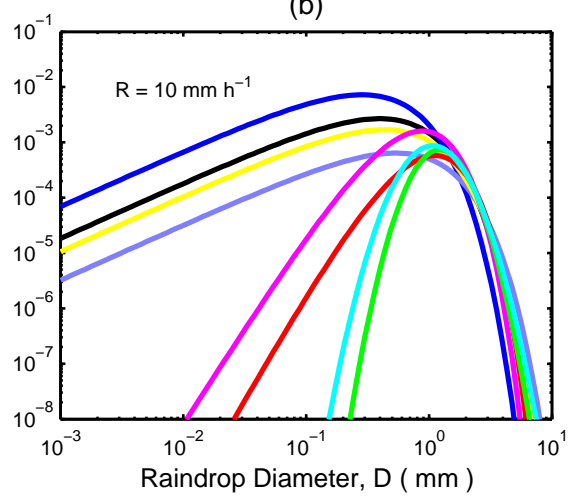

Fig. 4. Eight different raindrop number size distributions for rainfall intensities of (a) $R=0.1 \mathrm{~mm} \mathrm{~h}^{-1}$, and (b) $R=10 \mathrm{~mm} \mathrm{~h}^{-1}$ : MP Marshall and Palmer (1948); JD - Joss et al. (1968) drizzle conditions; JT - Joss et al. (1968) thunderstorm conditions; ZH - Zhang et al. (2008); DE - de Wolf (2001); W84 - Willis (1984); FL - Feingold and Levin (1986); and CE - Cerro et al. (1997).

Also shown in Fig. 3 are $E\left(d_{p}, D_{p}\right)$ profiles calculated based on alternate schemes described by Park et al. (2005) and Croft et al. (2009), respectively. The scheme for collection efficiency given in Park et al. (2005) considers the collection mechanisms of Brownian diffusion, interception, and inertial impaction. The Brownian diffusion and interception formulas are based on Jung and Lee (1998) and the treatment of inertial impaction comes from Calvert (1984). By contrast, Croft et al. (2009) divided the raindrop collectors and the collected particles into different size ranges (i.e., $>300$, $300-42,42-10, \leq 10 \mu \mathrm{m}$ for collectors, $>10,10-0.5,0.5-0.2$, $\leq 0.2 \mu \mathrm{m}$ for collected particles) and calculated the collection efficiencies between collectors and collected particles of different sizes using a look-up table modified from Hall (1980). The modifications included incorporating additional collection efficiency data from Wang et al. (1978), representing Brownian diffusion collection for small collector/collectedparticle pairs according to Young (1993), and adopting interpolated values (between the values of calculated Brownian diffusion and the values from the original look-up table) for certain size ranges of collector/collected particles.

The differences in $\Lambda$ values in Fig. 3 between the Park et al. (2005) and Slinn (1983) schemes are small (i.e., within a factor of 2-5) for particles smaller than $0.05 \mu \mathrm{m}$ and larger than $5 \mu \mathrm{m}$ in diameter. However, the differences can be as large as two orders of magnitude for particles in the 1-4 $\mu \mathrm{m}$ diameter range. The much larger $\Lambda$ values predicted by the Park et al. (2005) scheme for this size range are caused by neglect of the critical Stokes number threshold in the inertial impaction mechanism. The $\Lambda$ values derived from the Croft et al. (2009) scheme are smaller by a factor of $2-5$ from the Slinn (1983) scheme for particles smaller than $2 \mu \mathrm{m}$ in diameter, larger by 1-2 orders of magnitude for particles around $3 \mu \mathrm{m}$, and very similar for particles larger than $10 \mu \mathrm{m}$. The large differences between Croft's and Slinn's parameterizations between 2 and $10 \mu \mathrm{m}$ were also caused by differences in their treatments of inertial impaction. The results presented in Fig. 3 thus suggest that the parameterization of collection efficiency between aerosol particles and falling raindrops is an important source of uncertainty in the calculation of the size-resolved scavenging coefficient, particularly for particle diameters between 0.01 and $3 \mu \mathrm{m}$.

Note that many early studies used a constant collection efficiency in parameterizeing $\Lambda$ (Scott, 1982; Mircea and Stefan, 1998), so for comparison purposes one constant collection efficiency is also shown in Fig. 3. Since raindrops are generally much bigger than aerosol particles and raindrop terminal velocities are generally much bigger than particle settling velocities, then $\left(D_{p}+d_{p}\right)^{2} \cong D_{p}^{2}$ and $V\left(D_{p}\right) \gg v\left(d_{p}\right)$ so that $E\left(d_{p}, D_{p}\right)$ becomes the only parameter in Eq. (2) that is a function of the collected particle diameter $d_{p}$. Therefore, if $E\left(d_{p}, D_{p}\right)$ is assumed to be a constant for a given raindrop size distribution, then $\Lambda$ will be close to a constant for all particle sizes and will only change with rainfall intensity R. Clearly, this method does not reflect the reality evident in Fig. 3 since it neglects the dependence of below-cloud scavenging processes on particle size.

\subsection{Sensitivity to raindrop number size distribution}

As discussed in Sect. 2.2, a number of different empirical formulas for the raindrop number size spectrum have been used in theoretical $\Lambda$ parameterizations in previous studies. To investigate the sensitivity of $\Lambda$ to the choice of raindrop size spectrum, eight empirical formulas were selected to calculate $\Lambda$ using Eq. (2). As shown in Fig. 4, these included four exponential distributions (MP, JD, JT and ZH), two gamma distributions (DE and W84), and two lognormal distributions (FL and $\mathrm{CE}$ ). An immediate observation from Fig. 4 is that the four exponential distributions yield greater numbers of small droplets compared to the other distributions. For example, according to Table 2 the percentage of droplets smaller than $0.1 \mathrm{~mm}$ in diameter for the MP distribution is 

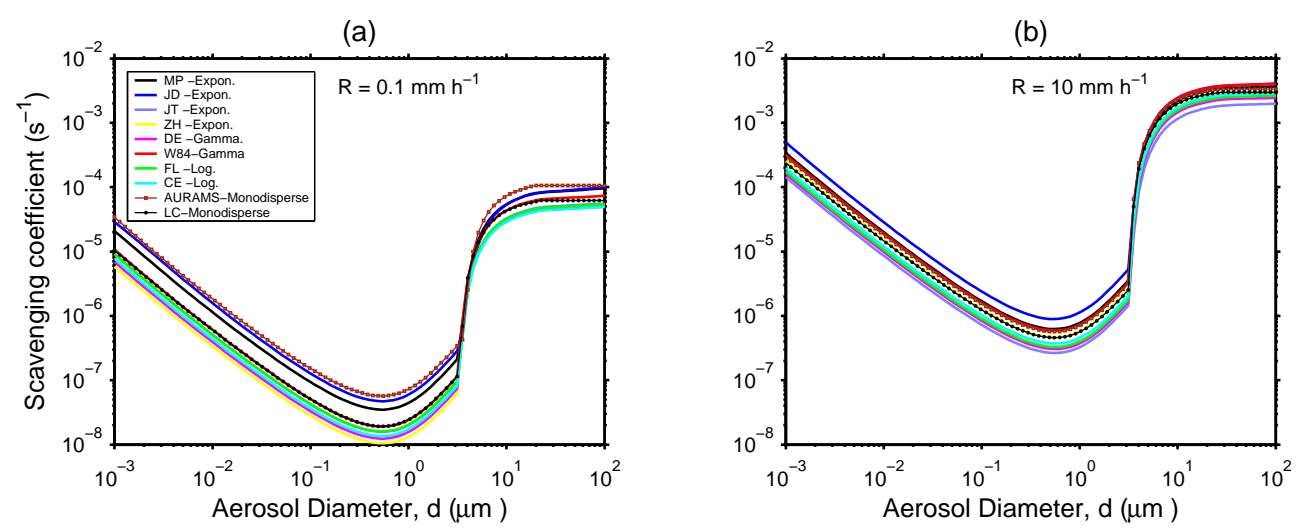

Fig. 5. Scavenging coefficients as a function of particle size derived from 10 different raindrop number size distributions for rainfall intensities of (a) $R=0.1 \mathrm{~mm} \mathrm{~h}^{-1}$ and (b) $R=10 \mathrm{~mm} \mathrm{~h}^{-1}$ : MP - Marshall and Palmer (1948); JD - Joss et al. (1968) drizzle conditions; JT - Joss et al. (1968) thunderstorm conditions; ZH - Zhang et al. (2008); DE - de Wolf (2001); W84 - Willis (1984); FL - Feingold and Levin (1986); CE - Cerro et al. (1997); AURAMS-Monodisperse - Gong et al. (2006); and LC-Monodisperse - Loosmore and Cederwall (2004).

Table 2. Total droplet number concentration, $N_{\text {total }}$, from three typical raindrop number size distributions for nine different rainfall intensities. MP denotes for Marshall and Palmer (1948), DE denotes de Wolf (2001), and FL denotes Feingold and Levin (1986).

\begin{tabular}{|c|c|c|c|c|c|c|c|c|c|}
\hline \multirow{2}{*}{$\begin{array}{l}R \\
\left(\mathrm{~mm} \mathrm{~h}^{-1}\right)\end{array}$} & \multicolumn{3}{|c|}{ MP (Exponential) } & \multicolumn{3}{|c|}{ DE (Gamma) } & \multicolumn{3}{|c|}{ FL (Lognormal) } \\
\hline & $N_{\text {total }}\left(\mathrm{m}^{-3}\right)$ & $f_{1}^{a}(\%)$ & $f_{2}^{b}(\%)$ & $N_{\text {total }}\left(\mathrm{m}^{-3}\right)$ & $f_{1}(\%)$ & $f_{2}(\%)$ & $N_{\text {total }}\left(\mathrm{m}^{-3}\right)$ & $f_{1}(\%)$ & $f_{2}(\%)$ \\
\hline 0.01 & 732.0 & 65.8 & 34.2 & 29.5 & 4.4 & 95.6 & 62.3 & 0.5 & 99.5 \\
\hline 0.1 & 1191.9 & 48.4 & 51.6 & 65.6 & 1.2 & 98.8 & 103.3 & 0.0 & 100.0 \\
\hline 1 & 1937.8 & 33.5 & 66.5 & 145.8 & 0.3 & 99.7 & 171.5 & 0.0 & 100.0 \\
\hline 5 & 2720.0 & 25.3 & 74.7 & 254.8 & 0.1 & 99.9 & 244.3 & 0.0 & 100.0 \\
\hline 10 & 3147.4 & 22.2 & 77.8 & 324.1 & 0.1 & 99.9 & 284.6 & 0.0 & 100.0 \\
\hline 20 & 3641.8 & 19.6 & 80.4 & 412.2 & 0.0 & 100.0 & 331.5 & 0.0 & 100.0 \\
\hline 50 & 4416.1 & 16.4 & 83.6 & 566.5 & 0.0 & 100.0 & 405.5 & 0.0 & 100.0 \\
\hline 70 & 4740.0 & 15.4 & 84.6 & 636.6 & 0.0 & 100.0 & 436.7 & 0.0 & 100.0 \\
\hline 100 & 5109.3 & 14.4 & 85.6 & 720.5 & 0.0 & 99.9 & 472.3 & 0.0 & 99.9 \\
\hline
\end{tabular}

$f_{1}$ is the percentage of the number concentration with the raindrop diameter less $0.1 \mathrm{~mm}$.

$f_{2}$ is the percentage of the number concentration with the raindrop diameter between 0.1 to $6 \mathrm{~mm}$.

$>65 \%$ in drizzle $\left(0.01 \mathrm{~mm} \mathrm{~h}^{-1}\right), 33 \%$ in moderate-intensity rain $\left(1 \mathrm{~mm} \mathrm{~h}^{-1}\right)$, and still $14 \%$ even in extremely heavy rain $\left(100 \mathrm{~mm} \mathrm{~h}^{-1}\right)$. By contrast, the gamma and lognormal distributions have fewer small droplets. For example, Table 2 shows that the percentages of droplets smaller than $0.1 \mathrm{~mm}$ in diameter for the DE gamma distribution and FL lognormal distribution are close to zero for all precipitation classes. As precipitation intensity increases, the modes of all of the distributions shift to larger drops (Fig. 4). The total droplet number concentration $\left(N_{\text {total }}\right)$ also increases with increasing rainfall intensity (Table 2). For a given rainfall intensity, the $N_{\text {total }}$ value predicted by the MP exponential distribution exceeds those predicted by the DE gamma distribution and FL lognormal distribution by an order of magnitude. However, the difference in $N_{\text {total }}$ between DE and FL is smaller than a factor of 2 .
The significant differences amongst different representations of raindrop number size distribution should also affect the calculated size-resolved $\Lambda$ values. A study by Mircea et al. (2000) found only a weak sensitivity of $\Lambda$ to the raindrop size distribution. However, the two droplet spectra used by Mircea et al. (2000) were quite similar in nature; they were both derived from measurements in the same area (Mediterranean) and were both lognormal distributions. Figure 5 shows a comparison of size-resolved $\Lambda$ curves derived from the eight different raindrop size spectra considered in Fig. 4 for two different rainfall intensities $\left(0.1\right.$ and $\left.10 \mathrm{~mm} \mathrm{~h}^{-1}\right)$. Note that the terminal fall velocities and collection efficiencies used in the calculations for this figure followed the theoretical formulas of Beard (1976) and Slinn (1983), respectively. 


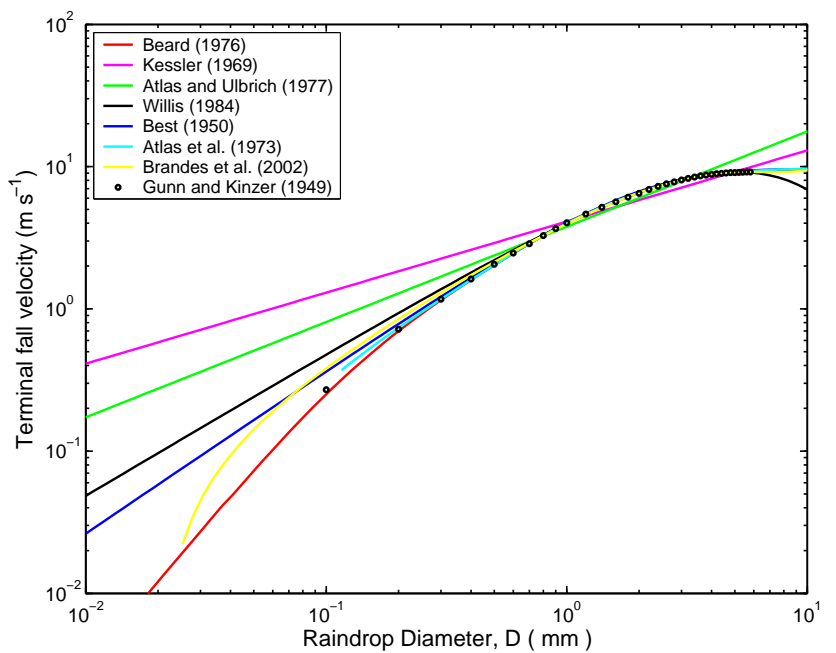

Fig. 6. Raindrop terminal velocity versus raindrop diameter for seven different parameterizations and measurements from Gunn and Kinzer (1949).

Clearly, $\Lambda$ depends strongly on the choice of raindrop number size distribution. $\Lambda$ values calculated using different raindrop size spectra can differ by a factor of 3 to 5 depending on particle size and precipitation intensity. The differences are more evident for particles smaller than $3 \mu \mathrm{m}$ under weak rainfall intensities. The MP and the JD raindrop size distributions give higher $\Lambda$ values than other distributions for all particle sizes for two reasons: (a) their higher droplet total number concentrations and (b) their greater fraction of small droplets, which have higher collection efficiencies (see Table 2 and Fig. 2). As rainfall intensity increases, however, the differences in droplet total number concentration and fraction of small droplets between the different raindrop size spectra decrease (see Table 2) because the modes of all distributions shift to larger droplet sizes (see Fig. 4). Thus, differences in $\Lambda$ from using different raindrop size spectra decrease with increasing rainfall intensity.

Section 2.2 mentioned that many large-scale aerosol transport models use a monodisperse distribution by introducing a representative diameter $D_{p}$ to replace the actual raindrop size distribution in the calculation of $\Lambda$ (e.g., Gong et al., 2003; Gong et al., 2006; Loosmore and Cederwall, 2004; Tost et al., 2006). This simplified approach (as shown in Eq. 14) assumes that the $\Lambda$ values calculated with $D_{p}$ would be similar to those calculated using a full raindrop size spectrum. A power-law function of the precipitation intensity has commonly been used to parameterize $D_{p}$ (e.g., $D_{p}=A R^{B}$, where $A$ and $B$ are constant and $R$ is the rainfall intensity). At present, there exist several parameterizations for $D_{p}$ in the literature (see Sportisse, 2007).

Two $\Lambda$ profiles generated based on two different $D_{p}$ formulas are shown in Fig. 5. One monodisperse distribution is used in AURAMS (A Unified Regional Air-quality

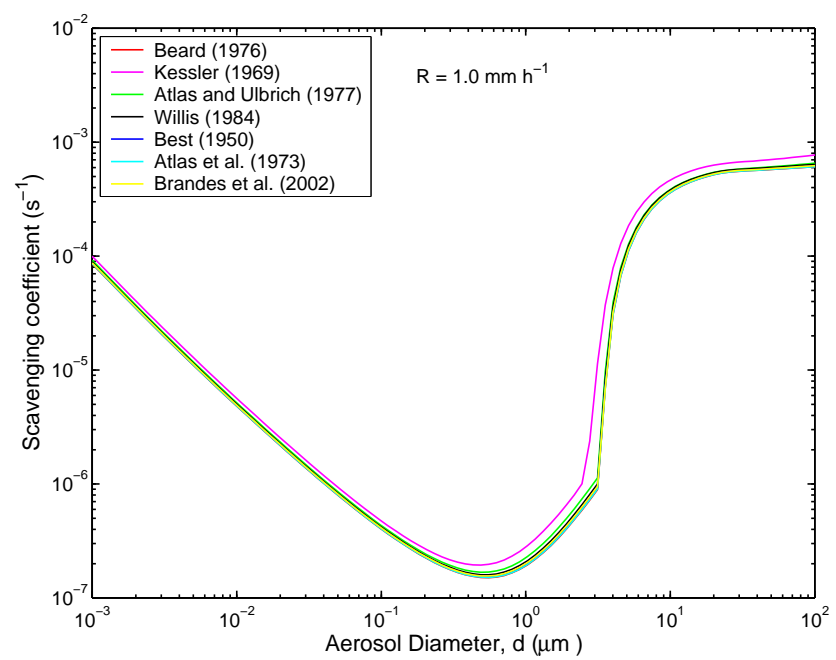

Fig. 7. Size-resolved scavenging coefficients as a function of particle size for seven different terminal velocity parameterizations assuming a rainfall intensity of $1.0 \mathrm{~mm} \mathrm{~h}^{-1}$.

Modelling System), where $D_{p}$ is parameterized as $D_{p}=$ $0.7 R^{0.25}$ (with $D_{p}$ in $\mathrm{mm}$ and $R$ in $\mathrm{mm} \mathrm{h}^{-1}$ ) (Gong et al., 2003; Gong et al., 2006; hereafter referred to as AURAMSMonodisperse), and the other one is used in NARAC/LLNL (National Atmospheric Release Advisory Center system of the Lawrence Livermore National Laboratory), where $D_{p}=$ $0.97 R^{0.158}$ (Loosmore and Cederwall, 2004; hereafter referred to as LC-Monodisperse). It can be seen that the $\Lambda$ values generated from these two simplified approaches are similar to those obtained from a full integration over a polydisperse droplet size spectrum. As well, the difference in $\Lambda$ from using the two different $D_{p}$ formulas is as large as from using different polydisperse droplet size spectra. For example, for a rainfall intensity of $0.1 \mathrm{~mm} \mathrm{~h}^{-1}$ (Fig. 5a), the $D_{p}$ difference is $0.28 \mathrm{~mm}$ (a factor of 1.7) and the corresponding $\Lambda$ difference is about a factor of 5; for a rainfall intensity of $10 \mathrm{~mm} \mathrm{~h}^{-1}$ (Fig. $5 \mathrm{~b}$ ), the $D_{p}$ difference is $0.15 \mathrm{~mm}$ (a factor of 1.1) and the corresponding difference in $\Lambda$ is smaller than a factor of 2 . Note also that the LC-Monodisperse "representative droplet diameter" was generated from the W84 droplet size spectrum (Willis, 1984). Interestingly, the $\Lambda$ values obtained from using these two distributions are very close to each other, suggesting that the use of a monodisperse raindrop size distribution can be a reasonable assumption as long as the proper representative diameter is chosen.

\subsection{Sensitivity to raindrop terminal velocity}

Figure 6 shows the terminal fall velocities of rain droplets derived from the six empirical formulas listed in Table 1 and the Beard theoretical scheme as well as the measurements reported by Gunn and Kinzer (1949). Note that the formulas from Atlas et al. (1973) and Brandes et al. (2002) give 
negative values when a droplet has a diameter smaller than $0.1 \mathrm{~mm}$ and $0.02 \mathrm{~mm}$, respectively. It can be seen that most formulas, except the power law formula of Kessler (1969), agree well with the experimental data for droplets in the $0.5 \mathrm{~mm}$ to $5 \mathrm{~mm}$ size range. For droplets larger than $5 \mathrm{~mm}$, however, different formulas produce quite different terminal velocities (e.g., 20-50\% difference depending on size); but droplets at these sizes are very rare. For droplets smaller than $0.5 \mathrm{~mm}$ (i.e., in the Stokes and lower transitional regimes), most formulas overestimate the fall speed. Noted that the theoretical formula of Beard (1976) agrees best with the experimental data.

The influence of different $V\left(D_{p}\right)$ formulas on the $\Lambda$ values is illustrated in Fig. 7 for a rainfall intensity $R$ of $1 \mathrm{~mm} \mathrm{~h}^{-1}$. The droplet size spectrum used in this calculation was the MP distribution and the collection efficiency formulation was Slinn's (1983) scheme. It can be seen that the uncertainty in $\Lambda$ from using different $V\left(D_{p}\right)$ formulas is generally within a factor of 2 for any particle size, much smaller than uncertainties caused by the choice of different droplet-particle collection efficiencies and different droplet size spectra. The formulas that give higher $V\left(D_{p}\right)$ values also tend to give higher $\Lambda$ values. For example, the MP droplet distribution has a large number of small drops. Since the Kessler (1969) formula predicts the largest $V\left(D_{p}\right)$ values for small droplets, it also produces the largest $\Lambda$ values (compare Fig. 7 with Fig. 6). Similar results to the above have also been obtained for gamma and lognormal droplet size spectra. It is also worth noting that for different rainfall intensities (figures not shown), sensitivity tests have shown the difference in $\Lambda$ values from using different $V\left(D_{p}\right)$ formulas decreases with increasing rainfall intensity. The largest uncertainty occurs for conditions of very weak rain (i.e., drizzle rain) due to the high concentrations of small droplets. In this case, the difference is still within a factor of 2 for all particle sizes.

\section{Evaluation of existing theoretical and empirical size-resolved $\Lambda$ parameterizations}

Available size-resolved $\Lambda$ parameterizations existing in the literature can be classified into three types based on how they were developed. The first type (hereafter referred to as Type I) calculates $\Lambda$ based on analytical formulas for raindropparticle collection efficiency, raindrop size distribution, and raindrop terminal velocity (e.g., Slinn, 1983; Mircea et al., 2000; Chate et al., 2003; Chate, 2005; Andronache, 2003; Andronache et al., 2006; Jung et al., 2003; Gong et al. 2003; Loosmore and Cederwall, 2004; Park et al., 2005; Tost et al., 2006; Feng, 2007; Croft et al., 2009). Sections 2 and 3 dealt with this first type of size-resolved $\Lambda$ parameterization. The second type (hereafter referred to as Type II) employs an empirical fit of pre-calculated $\Lambda$ values that were generated using a Type I method with an assumed droplet size spectrum and other needed inputs. For example, Henzing et al. (2006) developed a simple size-dependent $\Lambda$ parameterization based on a three-parameter fit to a set of pre-calculated $\Lambda$ values (see details in Appendix A1). Thus, $\Lambda$ values from Type II parameterizations should be similar to those from Type I parameterizations. A major advantage of Type II methods should be a significant reduction in computational burden since they need only evaluate a simple fitting function rather than performing an explicit integration over the raindrop size spectrum; however, one possible drawback of this method is that it might only be valid for certain rain droplet spectra. The third type of $\Lambda$ parameterization (hereafter referred to as Type III) uses an empirical fit to $\Lambda$ values derived from field measurements (Laakso et al., 2003; Baklanov and Sorensen, 2001). Table 3 lists some available size-resolved $\Lambda$ parameterizations classified by these three types.

Figure 8 shows a comparison of predictions from these 12 parameterizations with each other and with available field measurements for three different rainfall intensities. The majority of the field data display a strong dependence of the $\Lambda$ values on particle size. Below-cloud scavenging is fastest for particles larger than a few microns in diameter, moderate for particles smaller than $0.01 \mu \mathrm{m}$, and slowest for particles in the 0.1-1 $\mu \mathrm{m}$ diameter range. For example, the observed $\Lambda$ values were around $1 \times 10^{-4} \mathrm{~s}^{-1}$ to $3 \times 10^{-4} \mathrm{~s}^{-1}$ on average for particles in the $3.5-10 \mu \mathrm{m}$ diameter range (Volken and Schumann, 1993), around $1 \times 10^{-4} \mathrm{~s}^{-1}$ for particles smaller than $0.01 \mu \mathrm{m}$ (Davenport and Peters, 1978), and around $1 \times 10^{-5} \mathrm{~s}^{-1}$ on average for particles in the $0.1-1 \mu \mathrm{m}$ diameter range (Laakso et al., 2003). The measurement data also have a large spread, which is probably due to the very different experimental conditions between these field studies. In general, $\Lambda$ values were determined by measuring concentration changes of the size-resolved aerosol particle at ground stations before, during, and after rain events (e.g., Davenport and Peters, 1978; Slinn, 1983; Volken and Schumann, 1993; Laakso et al., 2003; Chate and Pranesha, 2004). Besides the measurement errors caused by the instruments and analysis processes, many other physical (horizontal and vertical advection and turbulent diffusion), microphysical (condensation, nucleation, coagulation, and hygroscopic growth), and chemical (both gas- and aqueous-phase chemistry) processes can modify particle concentrations concurrently and thus contribute to the large uncertainties in the measured $\Lambda$ values. Since particles in the $0.1-1 \mu \mathrm{m}$ diameter range have the smallest $\Lambda$ values, it is not surprising that the largest spread of $\Lambda$ values was also observed for this size range due to the various processes mentioned above.

To eliminate some of the uncertainties existing in the natural environment, a so-called outdoor experiment was designed by Sparmacher et al. (1993) to determine the belowcloud snow and rain scavenging coefficients using monodisperse artificial particles. In this experiment, monodisperse artificial aerosol particles from an aerosol generator were fed into a wind-shielded measuring chamber and suspended. Natural precipitation that fell through the chamber then 
(a)

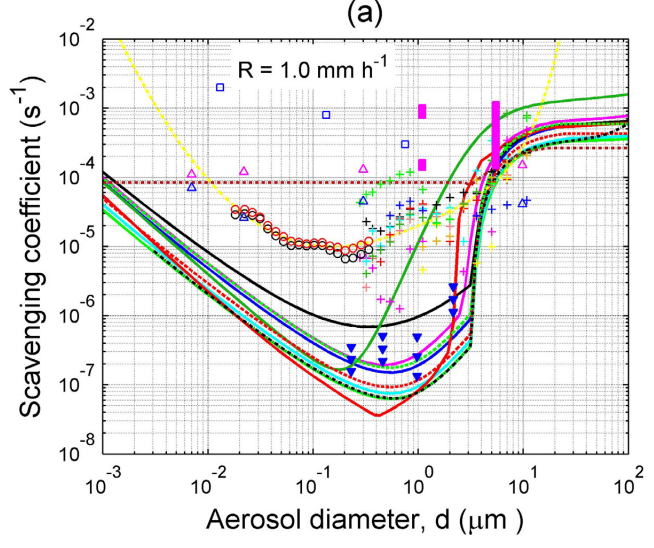

(c)

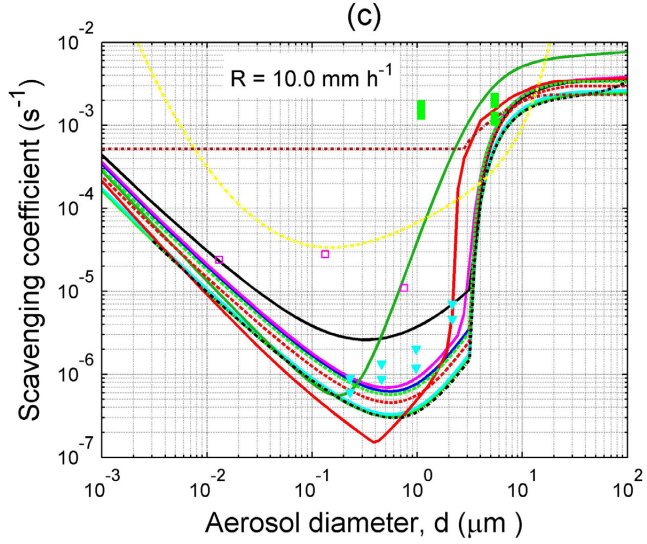

(b)

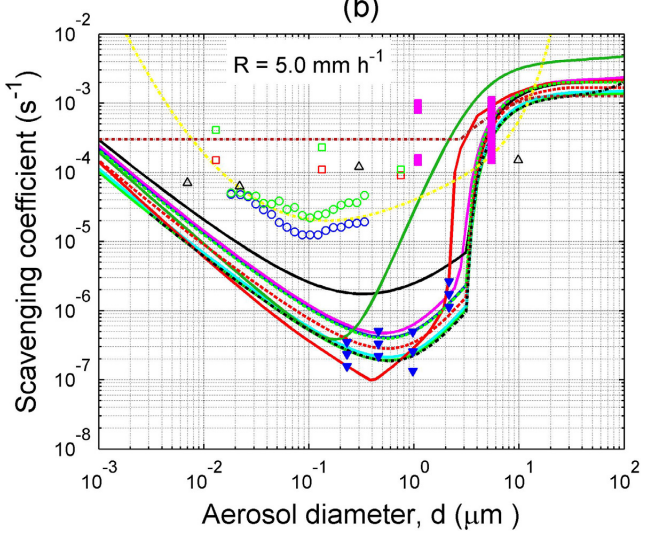

Volken and Schumann (1993), R=0.22 mm/h — Feng (2007)

Volken and Schumann (1993), R=0.41 mm/h - Andronache (2003)

Volken and Schumann (1993), $\mathrm{R}=0.46 \mathrm{~mm} / \mathrm{h} \quad$ - Calderon et al. (2008)

Volken and Schumann (1993) $\mathrm{R}=0.87 \mathrm{~mm} / \mathrm{h}$ - Mircea et al. (2000)

Volken and Schumann (1993), $R=0.91 \mathrm{~mm} / \mathrm{h}$ 二 Park et al (2005)

Volken and Schumann (1993), R=1.09 mm/h 二 Croft et al. (2009)

Volken and Schumann (1993), $R=1.14 \mathrm{~mm} / \mathrm{h} \quad$ L Losmore and Cederwall (2004) (Dp=0 07R 0158

Volken and Schumann (1993), $\mathrm{R}=1.30 \mathrm{~mm} / \mathrm{h}=$ - AURAMS $\left(\mathrm{D} p=0.7 \mathrm{R}^{0.25}\right)$

Volken and Schumann (1993), R=1.58 mm/h n.......... AURAMS $\left(\mathrm{Dp}=0.7 \mathrm{R}^{0.25}\right.$

Laakso et al. (2003), $R=0.78 \mathrm{~mm} / \mathrm{h}$

Laakso et al. (2003), $R=2.84 \mathrm{~mm} / \mathrm{h}$

Laakso et al.(2003), $R=6.83 \mathrm{~mm} / \mathrm{h}$

Slinn(1983), $R=0.5-5.0 \mathrm{~mm} / \mathrm{h}$

Slinn (1983), R=5.0-12.0 mm

Sparmacher et al. (1993), $R=0.5-5.0 \mathrm{~mm} / \mathrm{h}$

Sparmacher et al. (1993), $R=5.0-12.0 \mathrm{~mm} / \mathrm{h}$

Chate and Pranesha (2004), $R=0.9 \mathrm{~mm} / \mathrm{h}$

Chate and Pranesha (2004), $R=6.78 \mathrm{~mm} / \mathrm{h}$

Chate and Pranesha (2004), R=15.78 mm/h

Davenport and Peters (1977), R=1.1 mm/h

Davenport and Peters (1977), R=1.6 mm

Davenport and Peters (1977), R=3.0 mm/h

-..."' Henzing et al. (2006)

........ Baklanov and Serensen (2001)

Fig. 8. Scavenging coefficients as a function of aerosol diameter calculated from ten theoretical and two empirical $\Lambda$ parameterizations listed in Table 3 and taken from available measurements for rainfall intensities of (a) $R=1 \mathrm{~mm} \mathrm{~h}^{-1}$, (b) $R=5 \mathrm{~mm} \mathrm{~h}^{-1}$, and (c) $R=10 \mathrm{~mm} \mathrm{~h}^{-1}$. Note that the parameterization of Laakso et al. (2003) is only valid for particles with diameters between 0.01 and $0.5 \mu \mathrm{m}$.

scavenged the aerosol particles and $\Lambda$ values were then determined by measuring the changes of particle concentrations inside the chamber. The objective of the design of the experimental was to eliminate as many confounding factors during the scavenging process as possible so that the $\Lambda$ values observed would represent the actual droplet-particle collection processes (Sparmacher et al., 1993). The $\Lambda$ values for four selected particle sizes $(0.23,0.46,0.98$, and $2.16 \mu \mathrm{m}$ in diameter) generated from this study are also shown in Fig. 8. Interestingly, $\Lambda$ values from the 'outdoor' experiment are much lower than those determined from other field observations, suggesting that the above-mentioned physical and chemical processes do contribute substantially, and on many occasions play a dominant role, resulting in much higher measured $\Lambda$ values.

Figure 8 shows that for large particles $\left(d_{p}>3 \mu \mathrm{m}\right)$ the $\Lambda$ values from the theoretical parameterizations (Type I and II) agree well overall with field measurements under various rainfall intensities. However, all theoretical parameterizations, except the one of Park et al. (2005) that neglects the critical Stokes number for inertial impaction, underestimate observed $\Lambda$ values by one to two orders of magnitude for particles in the $0.1-3 \mu \mathrm{m}$ diameter range and by one order of magnitude for particles smaller than $0.1 \mu \mathrm{m}$ compared to the available field measurements. Although the parameterization of Andronache et al. (2006) takes into account the additional collection processes due to thermophoresis, diffusiophoresis, and electrostatic forces and uses the MP raindrop spectrum, which produces higher $\Lambda$ values than the other distributions (see Table 3 and Figs. 5 and 8), the discrepancies between the field observed and the theoretical predicted $\Lambda$ values are still more than one order of magnitude for particles in the $0.1-3 \mu \mathrm{m}$ diameter range (see Fig. 8). Figure 8 also suggests that the current theoretical parameterizations (Types I and II) seem to be able to correctly predict the droplet-particle collection process in an ideal vertical flow field created by raindrops as can be seen from the good agreement between theoretical values and results from the controlled experiment of Sparmacher et al. (1993). However, in the real world, other processes mentioned above appear to play dominant roles in the overall scavenging process as can be seen from the much higher $\Lambda$ values found in most field measurements compared to the controlled experiment of Sparmacher et al. (1993). 
Table 3. Current size-resolved $\Lambda$ parameterizations for below-cloud particle scavenging by rain. Type I denotes a theoretical parameterization with raindrop-particle collection efficiency, raindrop size distribution, and raindrop terminal velocity as component parameterizations, Type II denotes a pre-calculated empirical fit to a theoretical $\Lambda$ parameterization, and Type III denotes an empirical fit to field measurements.

\begin{tabular}{|c|c|c|c|c|}
\hline Source & $\begin{array}{l}\text { Raindrop-particle } \\
\text { collection effi- } \\
\text { ciency }\end{array}$ & Raindrop number size distribution & Raindrop terminal velocity & Types \\
\hline Feng (2007) & Slinn (1983) & Marshall-Palmer (Exponential) & Theoretical calculation & Type I \\
\hline Andronache (2003) & Slinn (1983) & Marshall-Palmer (Exponential) & Kessler (1969) & Type I \\
\hline Calderon et al. (2008) & Slinn (1983) & Massambani and Morales (Gamma) & Theoretical calculation & Type I \\
\hline Mircea et al. (2000) & Slinn (1983) & $\begin{array}{l}\text { Feingold and Levin (1986) (Lognor- } \\
\text { mal) }\end{array}$ & Theoretical calculation & Type I \\
\hline Andronache et al. (2006) & $\begin{array}{l}\text { Slinn (1983) } \\
+ \text { phoresis } \\
\text { + electric forces }\end{array}$ & Marshall-Palmer (Exponential) & Atlas and Ulbrich (1977) & Type I \\
\hline Park et al. (2005) & $\begin{array}{l}\text { Brownian and } \\
\text { interception from } \\
\text { Jung and Lee } \\
\text { (1998) } \\
\text { Impaction from } \\
\text { Calvert (1984) }\end{array}$ & Marshall-Palmer (Exponential) & Kessler (1969) & Type I \\
\hline Croft et al. (2009) & $\begin{array}{l}\text { Brownian from } \\
\text { Young (1993) } \\
\text { Impaction from } \\
\text { a modified Hall } \\
(1980) \text { table }\end{array}$ & Marshall-Palmer (Exponential) & Theoretical calculation & Type I \\
\hline $\begin{array}{l}\text { Loosmore and Cederwall } \\
\text { (2004) }\end{array}$ & Slinn (1983) & $\begin{array}{l}\text { Monodisperse } \\
D_{p}=0.97 R^{0.158} \mathrm{~mm}\end{array}$ & Willis (1984) & Type I \\
\hline $\begin{array}{l}\text { AURAMS (Gong et al., } \\
\text { 2006) }\end{array}$ & Slinn (1983) & $\begin{array}{l}\text { Monodisperse } \\
D_{p}=0.7 R^{0.25} \mathrm{~mm}\end{array}$ & Theoretical calculation & Type I \\
\hline Henzing et al. (2006) & $\begin{array}{l}\text { Fitted functions } \\
\text { from explicit } \\
\text { calculation }\end{array}$ & & & Type II \\
\hline Laakso et al. (2003) & $\begin{array}{l}\text { Empirical formula } \\
\text { from observations }\end{array}$ & & & Type III \\
\hline $\begin{array}{l}\text { Baklanov and Sorensen } \\
(2001)\end{array}$ & $\begin{array}{l}\text { Empirical formula } \\
\text { from observations }\end{array}$ & & & Type III \\
\hline
\end{tabular}

One example of an important neglected process may be the enhanced scavenging due to turbulent flow fluctuations (e.g., Grover and Pruppacher, 1985; Khain and Pinsky, 1997; Andronache et al. 2006). Turbulent flow fluctuations may increase the relative motions between particles and smaller collector droplets and thereby enhance the collection efficiency. For example, Khain and Pinsky (1997) found that the collection efficiency was significantly enhanced due to turbulence for droplet collectors of $240 \mu \mathrm{m}$ in diameter and for particles of 8-12 $\mu \mathrm{m}$ in diameter. Although Vohl et al. (2001) found no enhancement of the collection efficiency for submicron particles collected by droplets with sizes between $692 \mu \mathrm{m}$ and $5760 \mu \mathrm{m}$ in diameter based on wind tunnel experiments, there are substantial numbers of smaller raindrops (e.g., $<600 \mu \mathrm{m}$ in diameter) existing in medium to light rain due to belowcloud evaporation and breakup of rain drops (see Table 2 and Fig. 4).
Turbulence in the atmospheric boundary layer also drives vertical diffusion, which can transfer some particles from the subcloud layer upwards into the cloud layer where they are then removed through in-cloud processes (Andronache et al., 2006). Turbulence and vertical diffusion should have a larger impact on raindrop scavenging of small particles than large particles (e.g., Khain and Pinsky, 1997). This also explains why the theoretical $\Lambda$ values agree quite well with most field measurements for particles larger than $3 \mu \mathrm{m}$ in diameter but are as much as one to two orders of magnitude smaller for particles smaller than $3 \mu \mathrm{m}$ when compared to field measurements (except for the controlled experiment of Sparmacher et al., 1993) (Fig. 8). More recently, Andronache et al. (2006) developed a simplified scavenging model for ultrafine particles with diameters less than $0.01 \mu \mathrm{m}$ that includes below-cloud scavenging processes, mixing of ultrafine particles from the boundary layer into cloud, cloud condensation 
nuclei activation, and in-cloud removal by rainfall. They applied their model to the observed data of Laakso et al. (2003) and found good agreement in the overall particle scavenging, suggesting the possible important roles of turbulent mixing, cloud droplet activation, and in-cloud scavenging on the observed below-cloud scavenging. The size-resolved $\Lambda$ values shown in Fig. 8 of Zhang et al. (2004), which were produced using a detailed cloud microphysics model (where the droplet-particle collection mechanisms were similar to those used in the theoretical $\Lambda$ parameterizations shown in Fig. 8, but where the vertical diffusion process was also considered) also seem to be much higher than the theoretical $\Lambda$ values shown in the present study. More theoretical and field studies are needed to better understand the particle removal mechanisms so that the large discrepancies between theoretical and observed results can be reduced.

The empirical formulas derived from measurements (Type III) fit well to the data from which the formulas were generated but not necessarily to other data sets. The parameterization of Baklanov and Sorensen (2001) (see details in Appendix A2) overestimated the $\Lambda$ values for particles smaller than $3 \mu \mathrm{m}$ in diameter when compared with the measurements of Laakso et al. (2003), Volken and Schumann (1993), and Sparmacher et al. (1993). This parameterization treats the $\Lambda$ as a function of rainfall intensity $R$ only and neglects its dependence on particle size for particles smaller than $2.8 \mu \mathrm{m}$ (Appendix A2), whereas most measurements of $\Lambda$ show a strong dependence on particle size (e.g., Fig. 8). The empirical formula of Laakso et al. (2003) (see details in Appendix A3) agrees well with most of the observational data; however, this parameterization is only valid for particles with sizes of $0.01-0.5 \mu \mathrm{m}$ and for rainfall intensities of $20 \mathrm{~mm} \mathrm{~h}^{-1}$ or less. Thus, this comparison also suggests that current empirical parameterizations for $\Lambda$ need to be developed further and need to be verified against new sets of measurement data across a wider range of different conditions. New laboratory experiments under controlled conditions will also be very useful to evaluate existing theoretical scavenging formulas (which only consider collection processes), especially considering that there is only one such experimental data set currently. Collection of new field data under different rain conditions and other environmental conditions is certainly also needed, considering the very small database on this topic that is currently available. Note, however, that field observation data may inherently include the influences of all non-collection physical processes discussed above. The existing empirically-derived formulas based on field observations thus might not be applicable to large-scale models directly since non-collection physical processes have already been included separately in these models.

\section{Impacts of the various $\Lambda$ parameterizations on below-cloud particle removal}

The ultimate goal of parameterizing $\Lambda$ is to use the parameterization to predict particle mass and number concentration changes through the precipitation scavenging process in aerosol transport models. We can expect uncertainties in representing $\Lambda$ to introduce corresponding uncertainties on the predicted particle concentrations. In this section, two different aerosol particle size distributions, representing marine and urban aerosol populations, respectively, were taken as examples to investigate the impact of different $\Lambda$ parameterizations on predicted particle concentrations. The initial size distribution for each aerosol type was described as a sum of three lognormal functions according to Jaenicke (1993). The time evolution of the particle number and mass concentrations was then calculated by integrating Eq. (1) with very small time steps $(10 \mathrm{~s})$ and a large number of size bins (100) for both rain droplets ( $1 \mu \mathrm{m}$ to $10 \mathrm{~mm}$ in diameter) and aerosol particles $(0.001 \mu \mathrm{m}$ to $100 \mu \mathrm{m})$ with a constant volume ratio between successive size bins.

Figure 9 shows the time evolution of the bulk (i.e., integrated over the entire particle size spectrum) particle number concentration and mass concentration for typical marine and urban aerosol populations for a total rainfall of $5 \mathrm{~mm}$ for three different rainfall intensities calculated using eight different $\Lambda$ parameterizations from Table 3 . The particle concentrations have been normalized to their initial values $\left(\mathrm{N}_{0}\right.$ of 202 and $1.37 \times 10^{5} \mathrm{~cm}^{-3}, \mathrm{M}_{0}$ of 16.1 and $101.7 \mu \mathrm{g} \mathrm{m}^{-3}$, respectively). Note that different $\mathrm{x}$-axis scales have been used to accommodate the three different rainfall durations. The six plain solid lines correspond to the six theoretical $\Lambda$ parameterizations and the two lines with symbols correspond to the two empirical $\Lambda$ parameterizations. We can see that for the same precipitation amount, $5 \mathrm{~mm}$ of rain, which is equivalent to $50 \mathrm{~h}$ of rain at $0.1 \mathrm{~mm} \mathrm{~h}^{-1}, 5 \mathrm{~h}$ at $1 \mathrm{~mm} \mathrm{~h}^{-1}$, and $6 \mathrm{~min}$ at $50 \mathrm{~mm} \mathrm{~h}^{-1}$, the differences between predicted bulk aerosol number and mass concentrations for different $\Lambda$ parameterizations (both theoretical and empirical) decrease with increasing rainfall intensity. The reason is that the differences in $\Lambda$ values decrease with increasing rainfall intensity (see discussions in Sect. 3).

For the bulk number concentrations, the differences among the six theoretical $\Lambda$ parameterizations are within 5\% after $2 \mathrm{~mm}$ of rain and within $10 \%$ after $5 \mathrm{~mm}$ of rain for both marine and urban aerosols under $R=1 \mathrm{~mm} \mathrm{~h}^{-1}$ condition; these numbers are doubled under $R=0.1 \mathrm{~mm} \mathrm{~h}^{-1}$ condition and reduced by half under $R=50 \mathrm{~mm} \mathrm{~h}^{-1}$ condition. The two empirical $\Lambda$ parameterizations predict much faster removal of small particles $\left(d_{p}<0.01 \mu \mathrm{m}\right)$, which dominate the bulk number concentration. The differences in the bulk number concentrations between theoretical and empirical $\Lambda$ parameterizations can be larger than a factor of 2 after 2 $5 \mathrm{~mm}$ of rain under $R=1-50 \mathrm{~mm} \mathrm{~h}^{-1}$ conditions and larger than a factor of 5 under $R=0.1 \mathrm{~mm} \mathrm{~h}^{-1}$ conditions (see the 

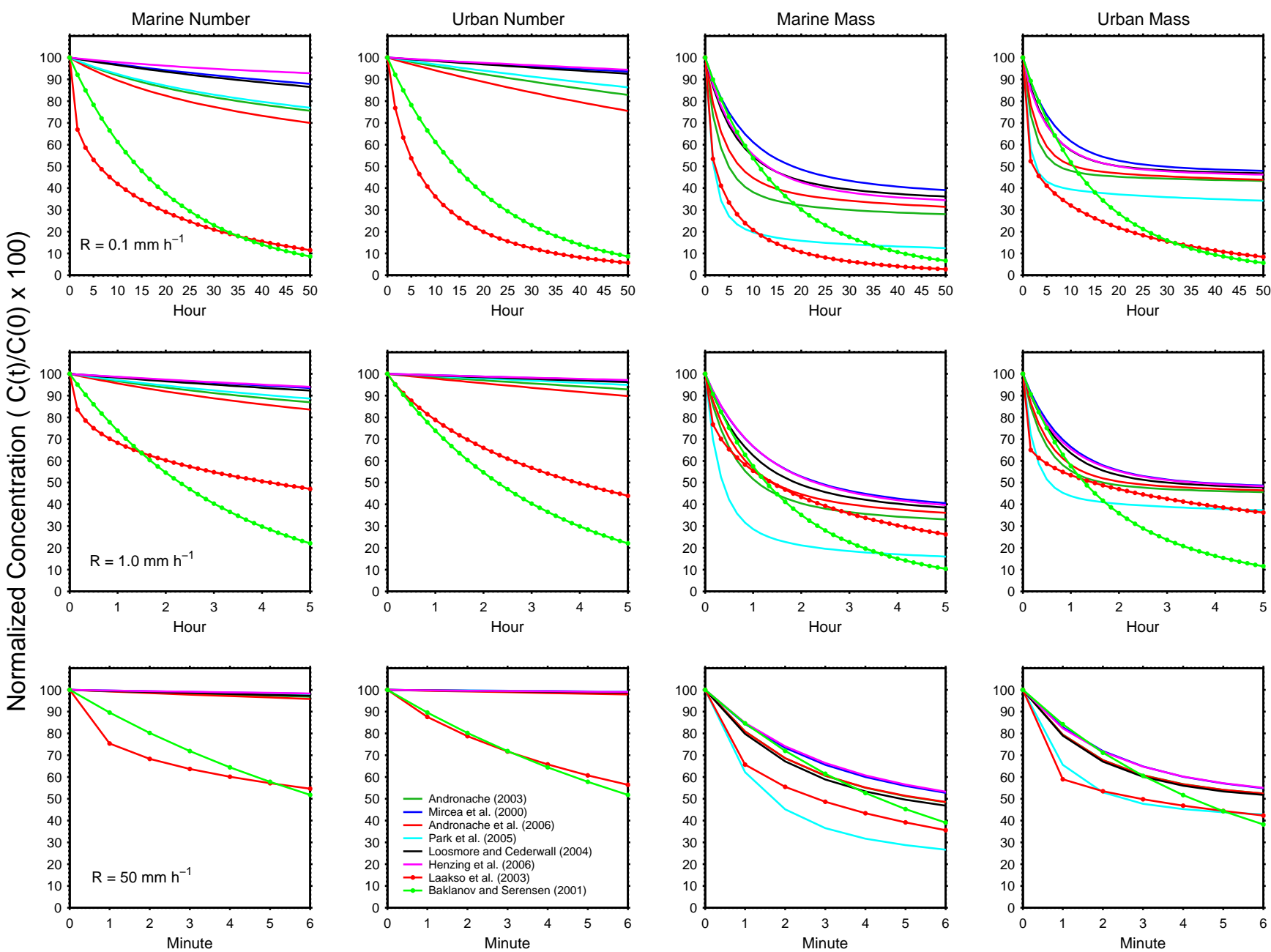

Fig. 9. Time evolution of the normalized bulk (i.e., integrated over the entire particle size spectrum) particle number concentration (first two columns) and mass concentration (last two columns) for typical marine and urban aerosol populations for a total rainfall of $5 \mathrm{~mm}$ for three different rainfall intensities, $0.1 \mathrm{~mm} \mathrm{~h}^{-1}$ (the first row), $1 \mathrm{~mm} \mathrm{~h}^{-1}$ (the second row), and $50 \mathrm{~mm} \mathrm{~h}^{-1}$ (the third row), calculated using eight different $\Lambda$ parameterizations from Table 3. The particle number and mass concentrations are normalized to their initial values. Plain solid lines denote theoretical $\Lambda$ parameterizations and lines with symbols denote empirical $\Lambda$ parameterizations.

first two columns in Fig. 9). For the bulk mass concentrations, the differences among the different $\Lambda$ parameterizations (both theoretical and empirical) can also be as large as a factor of 2 under $R=1-50 \mathrm{~mm} \mathrm{~h}^{-1}$ conditions and as large as a factor of 5-15 under $R=0.1 \mathrm{~mm} \mathrm{~h}^{-1}$ condition after 2$5 \mathrm{~mm}$ of rain (see last two columns in Fig. 9).

It is clear from Fig. 9 that the impacts of using different $\Lambda$ parameterizations are quantitatively different for the bulk number and mass concentrations. This is because the bulk mass concentration is generally associated with large particles whereas the bulk number concentration is associated with small particles, as can be seen from the initial particle size distributions shown in Fig. 10. For both marine and urban aerosol distributions, particles smaller than $1 \mu \mathrm{m}$ dominate the bulk number concentration while particles larger than $1 \mu \mathrm{m}$ dominate the bulk mass concentration. Thus, un- certainties in the $\Lambda$ parameterizations for particles smaller than $1 \mu \mathrm{m}$ contribute to the uncertainties in the predicted bulk number concentration whereas uncertainties in $\Lambda$ for particles larger than $1 \mu \mathrm{m}$ contribute to the uncertainties in the predicted bulk mass concentration, as discussed above for Fig. 9.

To confirm the above analysis, Fig. 10 shows the predicted size-resolved aerosol number and mass concentrations after two hours of precipitation with a rainfall intensity of $1 \mathrm{~mm} \mathrm{~h}^{-1}$ (using the same conditions as in Fig. 9). It can be seen that the largest differences from using different $\Lambda$ parameterizations are for ultrafine particles $\left(d_{p}<0.01 \mu \mathrm{m}\right)$ and for large particles $\left(d_{p}>3 \mu \mathrm{m}\right)$. For particles in the $0.01 \mu \mathrm{m}$ to $3 \mu \mathrm{m}$ diameter range, the differences are generally small, except for the Baklanov and Sorensen (2001) empirical parameterization, which had much higher $\Lambda$ values than the rest 

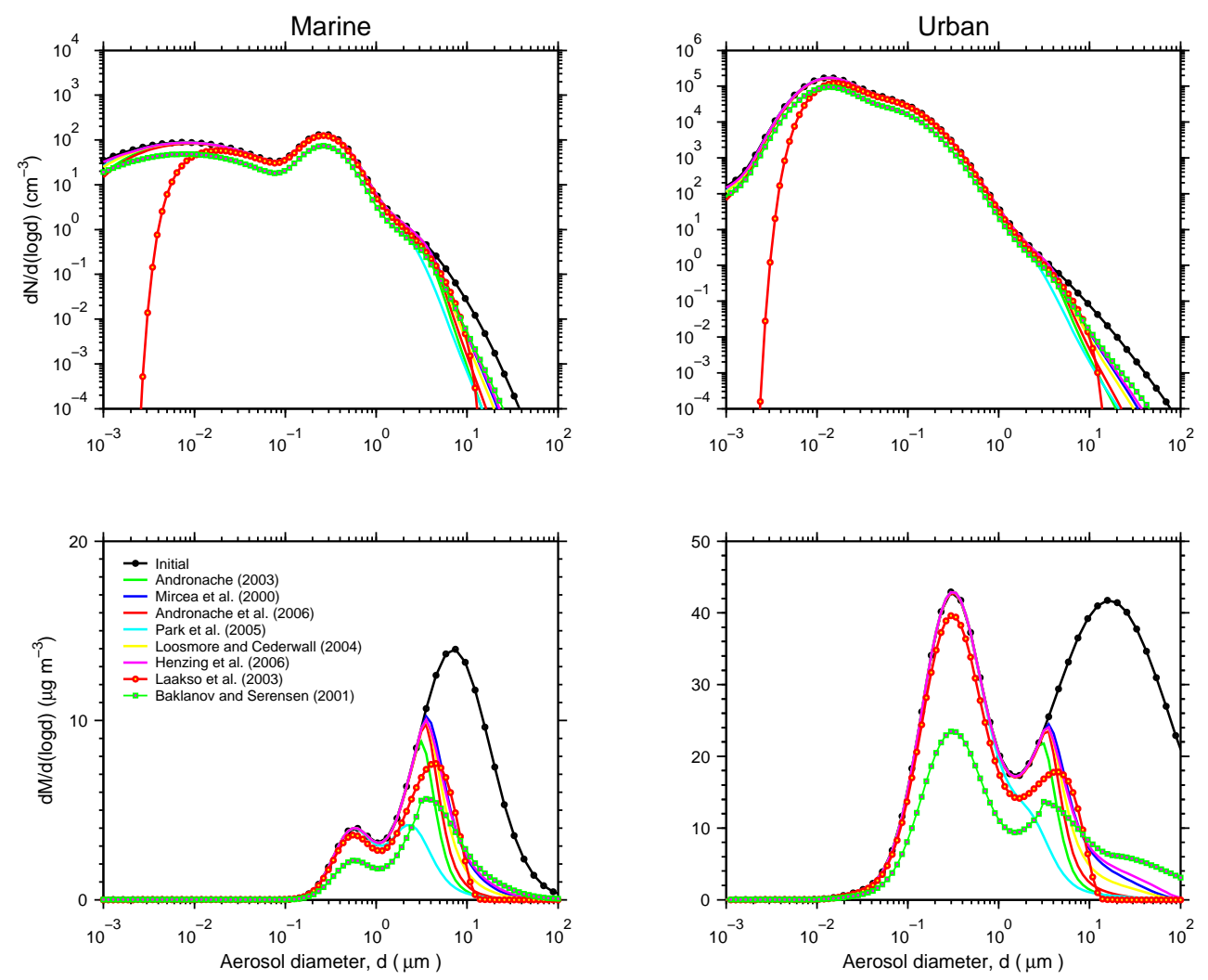

Fig. 10. Predicted size-resolved number (upper row) and mass (lower row) concentrations using six theoretical and two empirical $\Lambda$ parameterizations for typical marine and urban aerosol populations after two hours of rain with a rainfall intensity of $1 \mathrm{~mm} \mathrm{~h}^{-1}$. Note that different $\mathrm{y}$-axis scales have been used.

Table 4. Percentage removal for three particle sizes $(0.01,0.1$ and $1 \mu \mathrm{m})$ predicted based on three $\Lambda$ parameterizations after $5 \mathrm{~mm}$ of rain for three rainfall intensities $\left(50 \mathrm{~h}\right.$ at $0.1 \mathrm{~mm} \mathrm{~h}^{-1}, 5 \mathrm{~h}$ at $1 \mathrm{~mm} \mathrm{~h}^{-1}$, and $6 \mathrm{~min}$ at $50 \mathrm{~mm} \mathrm{~h}^{-1}$ ).

\begin{tabular}{lllllllllll}
\hline Rainfall Duration and Intensity & \multicolumn{3}{c}{$50 \mathrm{~h}$ at $0.1 \mathrm{~mm} \mathrm{~h}^{-1}$} & \multicolumn{3}{c}{$5 \mathrm{~h}$ at $1 \mathrm{~mm} \mathrm{~h}^{-1}$} & \multicolumn{3}{c}{$6 \mathrm{~min}$ at $50 \mathrm{~mm} \mathrm{~h}^{-1}$} \\
\hline$\Lambda$ Scheme $\backslash$ Particle Size & $0.01 \mu \mathrm{m}$ & $0.1 \mu \mathrm{m}$ & $1 \mu \mathrm{m}$ & $0.01 \mu \mathrm{m}$ & $0.1 \mu \mathrm{m}$ & $1 \mu \mathrm{m}$ & $0.01 \mu \mathrm{m}$ & $0.1 \mu \mathrm{m}$ & $1 \mu \mathrm{m}$ \\
Henzing et al. (2006) & 7.1 & 0.7 & 0.3 & 3.4 & 0.3 & 0.1 & 1.0 & 0.1 & 0.04 \\
Andronache et al. (2006) & 32.2 & 5.1 & 4.6 & 13.1 & 1.9 & 1.8 & 2.6 & 0.4 & 0.4 \\
Laakso et al. (2003) & 100.0 & 72.2 & 91.6 & 78.4 & 17.2 & 30.5 & 60.5 & 10.9 & 20.0 \\
\hline
\end{tabular}

of the parameterizations for this particle size range. For large particles $\left(3 \mu \mathrm{m}<d_{p}<10 \mu \mathrm{m}\right)$, the scavenging is very efficient, with $\Lambda$ values around $10^{-4}-10^{-3} \mathrm{~s}^{-1}$ for a rainfall intensity of $1 \mathrm{~mm} \mathrm{~h}^{-1}$ (see Fig. 8). A difference of a factor of 5 in $\Lambda$ values among the different $\Lambda$ parameterizations can lead to a difference of a factor of $>10$ in the predicted size-resolved aerosol particle concentration after $2 \mathrm{~mm}$ of rain (Fig. 10). For very small particles $\left(d_{p}<0.01 \mu \mathrm{m}\right)$, theoretical $\Lambda$ values are an order of magnitude lower (around between $10^{-5}$ and $10^{-4} \mathrm{~s}^{-1}$ ) than those for large particles (Fig.8). As a result, a difference of a factor of 3-5 in $\Lambda$ values results in differences of a factor of $<2$ in the predicted particle concentration after $2 \mathrm{~mm}$ of rain. For the same calculation, the empir- ical $\Lambda$ parameterizations can cause much larger differences (e.g., a factor of $\sim 10$ ) in the predicted particle concentrations for particles smaller than $0.01 \mu \mathrm{m}$ due to the much higher $\Lambda$ values. For particles in the 0.01 to $3 \mu \mathrm{m}$ diameter range, although the differences in $\Lambda$ values may be as large as 2 orders of magnitude, the resulting differences in the predicted size-resolved particle concentrations are very small. This is because the $\Lambda$ values in this size range are extremely small (i.e., $10^{-7}-10^{-5} \mathrm{~s}^{-1}$, Fig. 8), and thus, the below-cloud scavenging process plays an insignificant role during a light rainfall (e.g., $2 \mathrm{~mm}$ ). However, in the case of very intense rainfall (e.g., $R=50 \mathrm{mmh}^{-1}$ ) or cases of long-lasting rain with low or moderate intensities (e.g., $R=1-10 \mathrm{~mm} \mathrm{~h}^{-1}$ ), the scavenging 
(a)

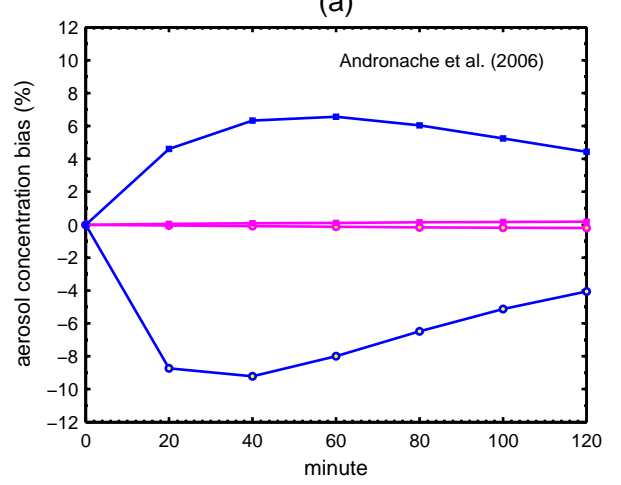

(b)

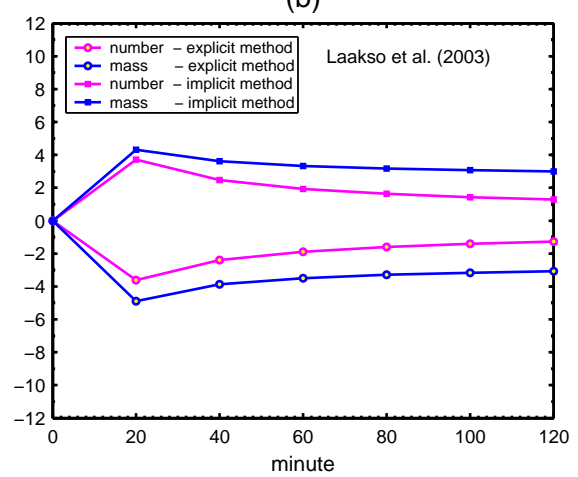

Fig. 11. Percentage bias from using an integration time step of 20 min relative to the results obtained using a time step of $10 \mathrm{~s}$. Two different size-resolved $\Lambda$ parameterizations, one theoretical (Andronache et al., 2006) and one empirical (Laakso et al., 2003), were considered. Rainfall intensity $R$ was chosen to be $1 \mathrm{~mm} \mathrm{~h}^{-1}$. Results are shown for both explicit (solid lines) and implicit (dashed lines) time integration schemes.

of particles in the 0.01 to $3 \mu \mathrm{m}$ diameter range can become important.

Table 4 shows the percentage of particles removed for three particle sizes $(0.01,0.1$, and $1 \mu \mathrm{m})$ after $5 \mathrm{~mm}$ of rain at three different intensities (i.e., $50 \mathrm{~h}$ of rain at $0.1 \mathrm{~mm} \mathrm{~h}^{-1}, 5 \mathrm{~h}$ at $1 \mathrm{~mm} \mathrm{~h}^{-1}$, and $6 \mathrm{~min}$ at $50 \mathrm{~mm} \mathrm{~h}^{-1}$ ) based on two theoretical $\Lambda$ parameterizations (the one with the highest $\Lambda$ and the one with the lowest $\Lambda$ from Fig. 8) and one empirical $\Lambda$ parameterization (Laakso et al., 2003). As can be seen from this table, for the theoretical $\Lambda$ parameterizations, $5 \mathrm{~mm}$ of rain removes only a small fraction (e.g., $<5 \%$ ) of particles sizes $0.1-1 \mu \mathrm{m}$. However, for the empirical $\Lambda$ parameterization, which is $1-2$ orders of magnitude higher than the theoretical schemes, $5 \mathrm{~mm}$ of rain can remove a very large fraction (e.g., $10-90 \%$ ) of particles in the $0.1-1 \mu \mathrm{m}$ diameter range. In the real world, the removal of particles from the atmosphere would be a coupled process involving droplet-particle collection, vertical transport (diffusion) of particles to low clouds and subsequent in-cloud removal, and many other processes (as reflected in the observational data that were used for deriving the empirical $\Lambda$ formulas). Thus, precipitation scavenging can also be significant for particles in the $0.01-3 \mu \mathrm{m}$ diameter range, as well as for very small or very large particles, especially during heavy rain or long-lasting rain (e.g., $\gg 5 \mathrm{~mm}$ of rain).

The above discussions suggested that the scavenging of very large particles $(>3 \mu \mathrm{m})$ and very small particles $(<0.01 \mu \mathrm{m})$ is a rapid process. This raises the question of whether the integration time step and the integration method employed above might introduce additional uncertainties in the prediction of particle concentrations. As an example, Fig. 11 shows the percentage bias of the calculated bulk particle number concentration and bulk particle mass concentration from using a time step of 20 min compared to the results using a time step of $10 \mathrm{~s}$. Results from both forward Euler (explicit) and backward Euler (implicit) methods are shown in the figure. Two different $\Lambda$ parameterizations were used here as examples: Andronache et al. (2006), representing a theoretical parameterization, and Laakso et al. (2003), representing an empirical parameterization. Rainfall intensity $\mathrm{R}$ was chosen to be $1 \mathrm{~mm} \mathrm{~h}^{-1}$. It can be seen that, in just one 20-min integration time step, an error of $>5 \%$ in mass concentration is introduced. Note that the larger the time step, the larger the errors will be. The explicit integration method underestimates the mass concentration (because the particle removed between $t$ and $t+\Delta t$ is based on concentration at time $t$ ) while the implicit method overestimates the mass concentration (because the particle removed between $t$ and $t+\Delta t$ is based on concentration at time $t+\mathrm{E} t$ ). It can also be seen that the error caused by using a large integration time step is larger for bulk particle mass concentration than for bulk particle number concentration due to the difference in $\Lambda$ values for large and small particles.

\section{Summary and conclusions}

To identify the sources of uncertainties in the current theoretical size-resolved $\Lambda$ parameterizations for below-cloud scavenging of particles by rain in atmospheric chemical transport models, a detailed literature review and set of numerical sensitivity tests in a common framework have been conducted in the present study. The largest uncertainties are associated with the specification of raindrop-particle collection efficiency. It was found that the use of different formulations for raindrop-particle collection efficiency can result in differences in the size-resolved $\Lambda$ values of nearly one to two orders of magnitude for particle diameters between 0.01-3 $\mu \mathrm{m}$. Inclusion of the additional collection mechanisms of thermophoresis, diffusiophoresis, and electrostatic forces in the Slinn (1983) scheme for droplet-particle collection efficiency, however, can enhance predicted $\Lambda$ values by nearly one order of magnitude for particle diameters between 
0.1-3 $\mu \mathrm{m}$. Another large source of uncertainty arises from the choice of raindrop number size distribution. Various raindrop number size distributions can yield $\Lambda$ values that differ by a factor of 3 to 5 depending on rainfall intensity and particle size. The uncertainty in $\Lambda$ caused by choosing different raindrop terminal velocity formulations is also not negligible but is generally smaller than a factor 2 .

Most current theoretical size-resolved $\Lambda$ parameterizations predict $\Lambda$ values that agree with the available measurements for particles larger than $3 \mu \mathrm{m}$ in diameter. For particles smaller than $3 \mu \mathrm{m}$, however, most current theoretical size-resolved $\Lambda$ parameterizations underpredict $\Lambda$ values by up to two orders of magnitude in comparison with the majority of field measurements. The combined uncertainty due to the use of different formulations of raindrop-particle collection efficiency, raindrop number size spectrum, and raindrop terminal velocity in the current theoretical framework, while considerable, is not sufficient to explain the large discrepancies between the theoretical and measured $\Lambda$ values. However, the large underprediction relative to most of the field data was not seen in the comparison with data from the controlled outdoor experiment reported by Sparmacher et al. (1993). This suggests that the additional known physical processes (i.e, turbulent transport and mixing, cloud and aerosol microphysics) that in general influence the field data but that are not taken into account in the current theoretical $\Lambda$ calculation may be a major source of the differences between the field and theoretical values. Thus, more laboratory experiments under controlled conditions are needed to evaluate the existing theoretical scavenging parameterizations. Further collection of field data under different rain conditions and other environmental conditions is certainly also needed, considering the very small database that is currently available on this topic. Moreover, numerical studies using comprehensive cloud models with explicit aerosol horizontal and vertical transport, turbulent diffusion, and detailed size-resolved microphysics are also needed to evaluate the importance of various terms and processes contributing to overall belowcloud scavenging.

The two empirical size-resolved $\Lambda$ parameterizations that were identified fit the field data from which they were generated well but do not necessarily fit other independent scavenging data sets well. In addition, they are only valid for a specific range of particle sizes and they may only apply to certain types of precipitation. Thus, more scavenging data are also needed to develop and extend these empirical parameterizations and to evaluate them under different rainfall conditions. Since the empirical parameterizations may inherently include the other non-collection physical processes such as turbulent transport, they may not be appropriate for use in large-scale chemical transport models where the noncollection physical processes are already included separately.

Uncertainties in the $\Lambda$ parameterizations can cause large differences in predicted bulk and size-resolved particle concentrations that are undergoing precipitation scavenging. For particles between $0.01-3 \mu \mathrm{m}$ in diameter, the differences in the predicted particle concentrations due to the use of different theoretical $\Lambda$ parameterizations are generally small ( $\sim$ a few percent), except under conditions of long-lasting precipitation, due to the very small $\Lambda$ values $\left(\ll 10^{-5} \mathrm{~s}^{-1}\right)$ predicted by the theoretical $\Lambda$ parameterizations. For particles smaller than $0.01 \mu \mathrm{m}$ in diameter, the differences can be substantial (up to a factor of 2 depending on particle size, precipitation intensity, and precipitation amount). The differences are largest ( $>$ factor of 10 after $2-5 \mathrm{~mm}$ of rain) for particles larger than $3 \mu \mathrm{m}$ due to the very large theoretical $\Lambda$ values $\left(>10^{-4} \mathrm{~s}^{-1}\right)$. If an empirical $\Lambda$ parameterization is used in place of a theoretical $\Lambda$ parameterization, differences in predicted particle concentrations can be larger than a factor of 2 for all particle sizes due to the very high $\Lambda$ values predicted by empirical $\Lambda$ parameterizations for all particle sizes. The predicted bulk mass concentrations can differ by a factor of 2 between theoretical and empirical $\Lambda$ parameterizations or even among the different theoretical $\Lambda$ parameterizations after $2-5 \mathrm{~mm}$ of rain. The predicted bulk number concentrations can also differ by a factor of 2 between theoretical and empirical $\Lambda$ parameterizations, however, the differences are generally within $10 \%$ among the different theoretical $\Lambda$ parameterizations under rain intensities of $1-50 \mathrm{~mm} \mathrm{~h}^{-1}$ and within $20 \%$ if the rain intensities are as small as $0.01 \mathrm{~mm} \mathrm{~h}^{-1}$.

Another uncertainty related to below-cloud particle scavenging in large-scale aerosol transport models is the choice of the time step in the integration of the number or mass continuity equation. If the concentration changes substantially over one model time step, then errors greater than 5\% may be introduced, particularly for very large particles (which control the bulk mass concentration), and very small particles (which control the bulk number concentration) due to their higher $\Lambda$ values.

Based on the results presented in this study, we can offer the following hypothesis: "The scavenging coefficients from the majority of field measurements that we examined were obtained at heights close to the surface where turbulence and vertical diffusion were strongest. These physical processes could have substantially enhanced particle removal both by increasing collection efficiency, and by transporting some particles upwards where they could then be scavenged by microphysical processes inside low clouds. These additional processes are likely to be the main cause of the large discrepancy between the theoretical and the field-derived values".

As a result, the empirical formulas for $\Lambda$ should be used with great caution in aerosol transport models since many additional processes that directly or indirectly contribute to the particle removal have already been considered separately. Current theoretical $\Lambda$ formulas can produce comparable $\Lambda$ values to those derived from controlled experiments (where additional processes contributing to particle removal were limited), and seem to be a reasonable choice for use in 
aerosol transport models. To construct a theoretical $\Lambda$ parameterization for use in aerosol transport models, we offer three recommendations: (1) Choose the theoretical $\Lambda$ parameterization that produces the highest $\Lambda$ values for particles in the $0.01-3 \mu \mathrm{m}$ diameter range. Even the highest $\Lambda$ values produced from theoretical formulas are still more than one order of magnitude smaller than the $\Lambda$ values derived from "non-controlled" field measurements (although slightly higher than the "controlled experiment", which should be reasonable considering that there are likely to be some processes that are not considered separately in aerosol transport models but that contribute to the particle scavenging process). This argues for using the highest theoretical collection efficiency, E, which means including all known collection mechanisms, including thermophoresis, diffusiophoresis, electrostatic forces, and turbulent enhancement; (2) Although a full droplet number size spectrum (the gamma function of de Wolf (2001) is preferred) is the best choice, the use of a monodisperse distribution and representative drop size in aerosol transport models should also be acceptable given that the uncertainties from such an approach are of a similar order of magnitude to those from other known or unknown processes. However, if a full droplet number size spectrum is used, then the theoretical formula of Beard (1976) is recommended for use in the calculation of raindrop terminal velocities since this formula provides a good estimate over the full range of raindrop sizes; (3) If in-cloud impaction scavenging is included, a different droplet number size spectrum (or representative particle size) from that used for below-cloud scavenging should be used since small droplets dominate within clouds.

\section{Appendix A}

\section{A1 Henzing et al. (2006) formula fitted from comprehensive numerical simulation}

Henzing et al. (2006) developed a simple parameterization that represents below-cloud scavenging coefficients as a function of aerosol particle size and rainfall intensity. The parameterization is a simple three-parameter fit through below-cloud scavenging coefficients calculated at high particle size resolution. The calculations were based on the concept of collection efficiency between polydisperse aerosol particles and raindrop distributions. Specifically, Slinn's semi-empirical formula was used for the raindrop-particle collection efficiency. The gamma function fit of de Wolf (2001) and the empirical formula of Atlas et al. (1973) were applied to represent the raindrop size distribution and the terminal fall velocity, respectively. The parameterization has been applied in a global chemical transport model. The final fitting function has the form

$\Lambda\left(d_{p}\right)=A_{0}\left(e^{A_{1} R^{A_{2}}}-1\right)$, where the parameters $A_{0}, A_{1}$ and $A_{2}$ are provided in a table that is available at http://www.knmi.nl/ velthove/wet_ deposition/coefficients.txt.

\section{A2 Baklanov and Sorensen (2001) empirical parame- terization}

Baklanov and Sorensen (2001) suggested a simple parameterization representing scavenging rate as a function of rainfall intensity and aerosol particle size based on earlier experiment data from several different groups:

$\Lambda\left(r_{p}\right)=$

$\begin{cases}a_{0} R^{0.79} & r_{p} \prec 1.4 \mu \mathrm{m} \\ \left(b_{0}+b_{1} r_{p}+b_{2} r_{p}^{2}+b_{3} r_{p}^{3}\right) f(R) & 1.4 \mu \mathrm{m} \prec r_{p} \prec 10 \mu \mathrm{m}, \\ f(R) & r_{p} \succ 10 \mu \mathrm{m}\end{cases}$

and

$f(R)=a_{1} R+a_{2} R^{2}$,

where $r_{p}$ is particle radius (in $\mu \mathrm{m}$ ), $a_{0}=8.4 \times 10^{-5}$, $a_{1}=2.7 \times 10^{-4}, \quad a_{2}=-3.618 \times 10^{-6}, \quad b_{0}=-0.1483$, $b_{1}=0.3220133, b_{2}=-3.0062 \times 10^{-2}, b_{3}=9.34458 \times 10^{-4}$, and $R$ is rainfall intensity (in $\mathrm{mm} \mathrm{h}^{-1}$ ). The parameterization has been incorporated into the Danish Emergency Response Model of the Atmosphere (DERMA).

\section{A3 Laakso et al. (2003) empirical parameterization}

Laakso et al. (2003) suggested a parameterization for $\Lambda\left(d_{p}\right)$ based on their analysis of six years of field measurements over forests in southern Finland:

$\log _{10} \Lambda\left(d_{p}\right)=$

$a_{1}+a_{2}\left[\log _{10} d_{p}\right]^{-4}+a_{3}\left[\log _{10} d_{p}\right]^{-3}+a_{4}\left[\log _{10} d_{p}\right]^{-2}+$

$a_{5}\left[\log _{10} d_{p}\right]^{-1}+a_{6} R^{1 / 2}$,

where $d_{p}$ is particle diameter (in $\mathrm{m}$ ), $\mathrm{a}_{1}=274.35758$, $\mathrm{a}_{2}=332839.59273, \quad \mathrm{a}_{3}=226656.57259, \quad \mathrm{a}_{4}=58005.91340$, $\mathrm{a}_{5}=6588.38582, \mathrm{a}_{6}=0.244984, R$ is rainfall intensity (in $\mathrm{mm} \mathrm{h}^{-1}$ ). The formula is valid only for limited ranges of particle diameters $0.01-0.5 \mu \mathrm{m}$ and for rain intensities $0-20 \mathrm{~mm} \mathrm{~h}^{-1}$. 


\section{Appendix B}

\section{Nomenclature}

\begin{tabular}{|c|c|}
\hline$C_{c}$ Cunningham correction factor & $q_{p}$ mean charge of a particle $(\mathrm{C})$ \\
\hline$c_{p}$ heat capacity of air $\left(\mathrm{m}^{2} \mathrm{~s}^{-2} \mathrm{~K}^{-1}\right)$ & $R$ rainfall intensity $\left(\mathrm{mmh}^{-1}\right)$ \\
\hline$d_{p}$ particle diameter $(\mathrm{m})$ & $R e$ raindrop Reynolds number \\
\hline$\underline{D}_{p}$ raindrop diameter $(\mathrm{m})$ & $R H$ relative humidity $(\%)$ \\
\hline $\bar{D}_{p}$ mean raindrop diameter of lognormal spectra (m) & $S c$ particle Schmidt number \\
\hline$D_{r}$ representative diameter of monodisperse & $S c_{w}$ Schmidt number for water in air \\
\hline raindrop spectra $(\mathrm{m})$ & $S t$ particle Stokes number \\
\hline 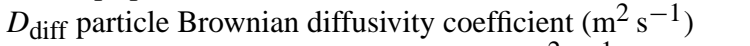 & $S t^{*}$ critical Stokes number of particle \\
\hline$D_{\text {diffwater }}$ water vapour diffusivity in air $\left(\mathrm{m}^{2} \mathrm{~s}^{-1}\right)$ & $T_{a}$ air temperature $(\mathrm{K})$ \\
\hline$E\left(d_{p}, D_{p}\right)$ overall collection efficiency & $T_{S}$ temperature of the raindrop surface $(\mathrm{K})$ \\
\hline$E_{t h}\left(d_{p}, D_{p}\right)$ collection efficiency due to thermophoresis & $v\left(d_{p}\right)$ particle terminal velocity $\left(\mathrm{m} \mathrm{s}^{-1}\right)$ \\
\hline$E_{d p h}\left(d_{p}, D_{p}\right)$ collection efficiency due to diffusiophoresis & $V\left(D_{p}\right)$ raindrop terminal velocity $\left(\mathrm{m} \mathrm{s}^{-1}\right)$ \\
\hline$E_{e s}\left(d_{p}, D_{p}\right)$ collection efficiency due to charge effect & $\beta_{g}$ slope parameter for gamma raindrop size \\
\hline $\begin{array}{l}g \text { Acceleration of gravity }\left(\mathrm{m} \mathrm{s}^{-2}\right) \\
k_{a} \text { thermal conductivity of air }\left(\mathrm{J} \mathrm{m}^{-1} \mathrm{~s}^{-1} \mathrm{~K}^{-1}\right)\end{array}$ & n \\
\hline$k_{p}$ thermal conductivity of particle $\left(\mathrm{J} \mathrm{m}^{-1} \mathrm{~s}^{-1} \quad \mathrm{~K}^{-1}\right)$ & size distribution \\
\hline$k_{b}$ Boltzmann constant $\left(\mathrm{J} \mathrm{K}^{-1}\right)$ & $\gamma$ shape parameter for gamma raindrop size \\
\hline$M_{a}$ air molecular weight & \\
\hline$M_{w}$ water vapour molecular weight & $\lambda$ mean free path of air molecules $(\mathrm{m})$ \\
\hline$N\left(D_{p}\right)$ raindrop number size distribution $\left(\mathrm{m}^{-4}\right)$ & $\Lambda\left(d_{p}\right)$ size-resolved scavenging coefficient of \\
\hline$N_{0 e}$ parameter for exponential raindrop size & particle $\left(\mathrm{s}^{-1}\right)$ \\
\hline distribution $\left(\mathrm{m}^{-4}\right)$ & $\mu_{a}$ air viscosity $\left(\mathrm{kg} \mathrm{m}^{-1} \mathrm{~s}^{-1}\right)$ \\
\hline$N_{0 g}$ parameter for gamma raindrop size & $\mu_{w}$ water viscosity $\left(\mathrm{kg} \mathrm{m}^{-1} \mathrm{~s}^{-1}\right)$ \\
\hline distribution $\left(\mathrm{m}^{-\gamma-1} \mathrm{~m}^{-3}\right)$ & $\rho_{a}$ air density $\left(\mathrm{kg} \mathrm{m}^{-3}\right)$ \\
\hline$N_{\text {total }}$ total number concentration of raindrops $\left(\mathrm{m}^{-3}\right)$ & $\rho_{p}$ particle density $\left(\mathrm{kg} \mathrm{m}^{-3}\right)$ \\
\hline$P$ atmospheric pressure $(\mathrm{Pa})$ & $\rho_{w}$ water density $\left(\mathrm{kg} \mathrm{m}^{-3}\right)$ \\
\hline Pr Prandtl number for air & $\sigma_{D}$ standard deviation of lognormal raindrop \\
\hline$P_{a}^{0}$ vapour pressure of water at temperature $\mathrm{T}_{a}(\mathrm{~Pa})$ & size distribution \\
\hline$P_{s}^{0}$ vapour pressure of water at temperature $\mathrm{T}_{S}(\mathrm{~Pa})$ & $\tau$ characteristic relaxation time of particle (s) \\
\hline
\end{tabular}

Acknowledgements. The authors wish to thank Lauri Laakso and Tiia Grönholm of the University of Helsinki for providing their observed scavenging data, Betty Croft of Dalhousie University for providing her collection efficiency code, and Paul Makar and Wanmin Gong of Environment Canada and two anonymous reviewers for providing very constructive comments on earlier versions of this paper.

Edited by: N. Riemer

\section{References}

Andronache, C.: Estimated variability of below-cloud aerosol removal by rainfall for observed aerosol size distributions, Atmos. Chem. Phys., 3, 131-143, doi:10.5194/acp-3-131-2003, 2003.

Andronache, C.: Diffusion and electric charge contributions to below-cloud wet removal of atmospheric ultra-fine aerosol particles, J. Aerosol Sci., 35, 1467-1482, 2004.

Andronache, C., Grönholm, T., Laakso, L., Phillips, V., and Venäläinen, A.: Scavenging of ultrafine particles by rainfall at a boreal site: observations and model estimations, Atmos. Chem. Phys., 6, 4739-4754, doi:10.5194/acp-6-4739-2006, 2006.
Atlas, D., Srivastava, R. C., and Sekhon, R. S.: Doppler radar characteristics of precipitation at vertical incidence, Rev. Geophys., $11,1-35,1973$.

Atlas, D. and Ulbrich, C. W.: Path and area-integrated rainfall measurement by microwave attenuation in the $1-3 \mathrm{~cm}$ band, J. Appl. Meteorol., 16, 1322-1331, 1977.

Bae, S. Y., Jung, C. H., and Kim, Y. P.: Development and evaluation of an expression for polydisperse particle scavenging coefficient for the below-cloud scavenging as a function of rain intensity using the moment method, J. Aerosol Sci., 37, 1507-1519, 2006.

Baklanov, A.: Parameterisation of the deposition processes and radioactive decay: a review and some preliminary results by the DERMA model, DMI Scientific Report 99-4, Danish Meteorological Institute, Copenhagen, Denmark, 1999.

Baklanov, A. and Sorensen, J. H.: Parameterisation of radionuclides deposition in atmospheric long-range transport modeling, Phys. Chem. Earth Pt. B, 26(9), 787-799, 2001.

Balkanski, Y. J., Jacob, D. J., Gardner, G. M., Graustein, W. C., and Turekian, K. K.: Transport and residence times of tropospheric aerosols inferred from a global three-dimensional simulation of ${ }^{210} \mathrm{~Pb}$, J. Geophys. Res., 98(D11), 20573-20586, 1993.

Beard, K. V.: Terminal velocity and shape of cloud and precipitation drops aloft, J. Atmos. Sci., 33, 851-864, 1976.

Best, A. C.: Empirical formulae for the terminal velocity of water 
drops falling through the atmosphere, Q. J. Roy. Meteor. Soc., 76, 302-311, 1950.

Brandes, E. A., Zhang, G., and Vivekanandan, J.: Experiments in rainfall estimation with a polarimetric radar in a subtropical environment, J. Appl. Meteorol., 41, 674-685, 2002.

Brandes, E. A., Zhang, G., and Vivekanandan, J.: Drop-size distribution retrieval with polarimetric radar: Model and application, J. Appl. Meteorol., 43, 461-475, 2004.

Brandes, E. A., Zhang, G., and Sun, J.: On the influence of assumed drop size distribution form on radar-retrieved thunderstorm microphysics, J. Appl. Meteorol. Clim., 45, 259-268, 2006.

Bringi, V. N., Chandrasekar, V., Hubbert, J., Gorgucci, E., Randeu, W. L., and Schoenhuber M.: Raindrop size distribution in different climatic regimes from disdrometer and dual-polarized radar analysis, J. Atmos. Sci., 60, 354-365, 2003.

Byrne, M. A. and Jennings, S. C.: Scavenging of sub-micrometer aerosol particles by water drops, Atmos. Environ., 27A, 20992105, 1993.

Calderon, S. M., Poor, N. D., Campbell, S. W., Tate, P., and Hartsell, B.: Rainfall scavenging coefficients for atmospheric nitric acid and nitrate in a subtropical coastal environment, Atmos. Environ., 42, 7757-7767, 2008.

Calvert, S.: Particle control by scrubbing, in: Handbook of air pollution technology, edited by Calvert, S., and Englund, H. M., Wiley, New York, 215-248, 1984.

Cerro, C., Codina, B., Bech, J., and Lorente, J.: Modelling raindrop size distribution and $\mathrm{Z}(\mathrm{R})$ relations in the Western Mediterranean Area, J. Appl. Meteorol., 36, 1470-1479, 1997.

Chate, D. M.: Study of scavenging of submicron-sized aerosol particles by thunderstorm rain events, Atmos. Environ., 39, 66086619, 2005.

Chate, D. M. and Pranesha, T. S.: Field studies of scavenging of aerosols by rain events, J. Aerosol Sci., 35, 695-706, 2004.

Chate, D. M., Rao, P. S. P., Naik, M. S., Momin, G. A., Safai, P. D., and Ali, K.: Scavenging of aerosols and their chemical species by rain, Atmos. Environ., 37, 2477-2484, 2003.

Croft, B., Lohmann, U., Martin, R. V., Stier, P., Wurzler, S., Feichter, J., Posselt, R., and Ferrachat, S.: Aerosol size-dependent below-cloud scavenging by rain and snow in the ECHAM5HAM, Atmos. Chem. Phys., 9, 4653-4675, doi:10.5194/acp-94653-2009, 2009.

Davenport, H. M. and Peters, L. K.: Field studies of atmospheric particulate concentration changes during precipitation, Atmos. Environ., 12, 997-1008, 1978.

de Wolf, D. A.: On the Laws-Parsons distribution of raindrop sizes, Radio Sci., 36, 639-642, 2001.

Feingold, G. and Levin, Z.: The lognormal fit to raindrop spectra from frontal convective clouds in Israel, J. Clim. Appl. Meteorol., 25, 1346-1363, 1986.

Feng, J.: A 3-mode parameterization of below-cloud scavenging of aerosols for use in atmospheric dispersion models, Atmos. Environ., 41, 6808-6822, 2007.

Gong, S. L., Barrie, L. A., Blanchet, J.-P., von Salzen, K., Lohmann, U., Lesins, G., Spacek, L., Zhang, L. M., Girard, E., Lin, H., Leaitch, R., Leighton, H., Chylek, P., and Huang P.: Canadian Aerosol Module: A size-segregated simulation of atmospheric aerosol processes for climate and air quality models: 1. Module development, J. Geophys. Res., 108(D1), 4007, doi:10.1029/2001JD002002, 2003.
Gong, W., Dastoor, A. P., Bouchet, V. S., Gong, S. L., Makar, P. A., Moran, M. D., Pabla, B., Ménard, S., Crevier, L.-P., Cousineau, S., and Venkatesh, S.: Cloud processing of gases and aerosols in a regional air quality model (AURAMS), Atmos. Res., 82, 248275, 2006.

Grover, S. N. and Pruppacher, H. R.: The effect of vertical turbulent fluctuations in the atmosphere on the collection of aerosol particles by cloud drops, J. Atmos. Sci., 42, 2305-2318, 1985.

Grover, S. N., Pruppacher, H. R., and Hamielec, A. E.: A numerical determination of the efficiency with which spherical aerosol particles collide with spherical water drops due to inertial impaction and phoretic and electric forces, J. Atmos. Sci., 34, 1655-1663, 1977.

Gunn, R. and Kinzer, G. D.: The terminal velocity of fall for water droplets in stagnant air, J. Meteorol., 6, 243-248, 1949.

Hall, W. D.: A detailed microphysical model within a two dimensional framework: model description and preliminary results, J. Atmos. Sci., 37, 2486-2507, 1980.

Henzing, J. S., Olivié, D. J. L., and van Velthoven, P. F. J.: A parameterization of size resolved below cloud scavenging of aerosol by rain, Atmos. Chem. Phys., 6, 3363-3375, doi:10.5194/acp-63363-2006, 2006.

Jacobson, M. Z.: Fundamentals of Atmospheric Modeling, $2^{\text {nd }}$ edition, Cambridge University Press, New York, USA, 813 pp., 2005.

Jacobson, M. Z.: Development of mixed-phase clouds from multiple aerosol size distributions and the effect of the clouds on aerosol removal, J. Geophys. Res., 108(D8), 4245, doi:10.1029/2002JD002691, 2003.

Jaenicke, R.: Tropospheric aerosols, in: Aerosol-cloud-climate interactions, edited by: Hobbs, P. V., Academic Press, San Diego, CA, USA, 1-31, 1993.

Jaworek, A., Adamiak, K., Balachandran, W., Krupa, A., Castle, P., and Machowski, W.: Numerical simulation of scavenging of small particles by charged droplets, Aerosol Sci. Tech., 36, 913924, 2002.

Joss, J., Thams, J. C., and Waldvogel, A.: The variation of raindrop size distributions at Locarno, in Proc. Internat. Conf. on Cloud Physics, Toronto, 369-373, 1968.

Jung, C. H. and Lee, K. W.: Filtration of fine particles by multiple liquid drop and gas bubble systems, Aerosol Sci. Tech., 29, 389401, 1998.

Jung, C. H., Kim, Y. P., and Lee, K. W.: A moment model for simulating raindrop scavenging of aerosols, J. Aerosol Sci., 34, 1217-1233, 2003.

Kessler, E.: On the distribution and continuity of water substance in atmospheric circulations, Meteorol. Monogr., 32, Am. Meteorol. Soc., Boston, USA, 84 pp., 1969.

Khain, A. P. and Pinsky, M. B.: Turbulence effects on the collision kernel, II: Increase of the swept volume of colliding drops, Q. J. Roy. Meteor. Soc., 123, 1543-1560, 1997.

Laakso, L., Grönholm, T., Rannik, U., Kosmale, M., Fiedler, V., Vehkamäki, H., and Kulmala, M.: Ultrafine particle scavenging coefficients calculated from 6 years field measurements, Atmos. Environ., 37, 3605-3613, 2003.

Loosmore, G. A. and Cederwall, R. T.: Precipitation scavenging of atmospheric aerosols for emergency response applications: testing an updated model with new real-time data, Atmos. Environ., 38, 993-1003, 2004. 
Marshall, J. S. and Palmer, W. M.: The distribution of raindrop with size, J. Meteorol., 5, 165-166, 1948.

McGann, B. T. and Jennings, S. G.: The efficiency with which drizzle and precipitation sized drops collide with aerosol particles, Atmos. Environ., 25A, 791-799, 1991.

Mircea, M. and Stefan, S.: A theoretical study of the microphysical parameterization of the scavenging coefficient as a function of precipitation type and rate, Atmos. Environ., 32, 2931-2938, 1998.

Mircea, M., Stefan, S., and Fuzzi, S.: Precipitation scavenging coefficient: influence of measured aerosol and raindrop size distributions, Atmos. Environ., 34, 5169-5174, 2000.

Park, S. H., Jung, C. H., Jung, K. R., Lee, B. K., and Lee, K. W.: Wet scrubbing of polydisperse aerosols by freely falling droplets, Aerosol Sci., 36, 1444-1458, 2005.

Pinsky, M. and Khain, A.: Collision efficiency of drops in a wide range of Reynolds numbers: Effects of pressure on spectrum evolution, J. Atmos. Sci., 58, 742-764, 2001.

Phillips, C. G. and Kaye, S. R.: The influence of the viscous boundary layer on the critical Stokes number for particle impaction near a stagnation point, J. Aerosol Sci., 30, 709-718, 1999.

Pranesha, T. S. and Kamra, A. K.: Scavenging of aerosol particles by large water drops 3 . Washout coefficients, half-lives, and rainfall depths, J. Geophy. Res., 102(D20), 23947-23953, 1997.

Pruppacher, H. R. and Klett, J. D.: Microphysics of clouds and precipitation, Kluwer Academic Publishers, Dordrecht, Boston, London, UK, 954 pp., 1997.

Rasch, P. J., Feichter, J., Law, K., Mahowald, N., Penner, J., Benkovitz, C., Genthon, C., Giannakopoulos, C., Kasibhatla, P., Koch, D., Levy, H., Maki, T., Prather, M., Roberts, D. L., Roelofs, G.-J., Stevenson, D., Stockwell, Z., Taguchi, S., Kritz, M., Chipperfield, M., Baldocchi, D., McMurry, P., Barrie, L., Balkanski, Y., Chatfield, R., Kjellstrom, E., Lawrence, M., Lee, H. N., Lelieveld, J., Noone, K. J., Seinfeld, J., Stenchikov, G., Schwartz, S., Walcek, C., and Williamson, D.: A comparison of scavenging and deposition processes in global models: Results from the WCRP Cambridge Workshop of 1995, Tellus, 52B, 1025-1056, 2000.

Sauvageot, H. and Lacaux, J.-P.: The shape of averaged drop size distributions, J. Atmos. Sci., 52, 1070-1083, 1995.

Scott, B. C.: Theoretical estimates of the scavenging coefficient for soluble aerosol particles as a function of precipitation type, rate and altitude, Atmos. Environ., 16, 1753-1762, 1982.

Seinfeld, J. H. and S. N. Pandis, Atmospheric chemistry and physics: from air pollution to climate change, Wiley \& Sons, New Jersey, 1203 pp., 2006.

Slinn, W. G. N.: Precipitation scavenging, in: Atmospheric Sciences and Power Production - 1979, chap. 11, Division of Biomedical Environmental Research, U.S. Department of Energy, Washington DC, USA, 1983.

Slinn, W. G. N. and Hales, J. M.: A reevaluation of the role of thermophoresis as a mechanism of in- and below-cloud scavenging, J. Atmos. Sci., 28, 1465-1471, 1971.

Slinn, W. G. N. and Shen, S. F.: Anisotropic Brownian diffusion and precipitation scavenging of submicron particles, J. Geophy. Res., 75(12), 2267-2270, 1970.

Sparmacher, H., Fulber, K., and Bonka, H.: Below-cloud scavenging of aerosol particles: Particle-bound radionuclides - Experimental, Atmos. Environ., 27A, 605-618, 1993.
Sportisse, B.: A review of parameterizations for modelling dry deposition and scavenging of radionuclides, Atmos. Environ., 41, 2683-2698, 2007.

Textor, C., Schulz, M., Guibert, S., Kinne, S., Balkanski, Y., Bauer, S., Berntsen, T., Berglen, T., Boucher, O., Chin, M., Dentener F., Diehl, T., Easter, R., Feichter, H., Fillmore, D., Ghan, S., Ginoux, P., Gong, S., Grini, A., Hendricks, J., Horowitz, L., Huang, P., Isaksen, I., Iversen, T., Kloster, S., Koch, D., Kirkevåg, A., Kristjansson, J. E., Krol, M., Lauer, A., Lamarque, J. F., Liu, X., Montanaro, V., Myhre, G., Penner, J., Pitari, G., Lamarque, J. F., Liu, X., Montanaro, V., Myhre, G., Penner, J., Pitari, G., Reddy, S., Seland, Ø., Stier, P., Takemura, T., and Tie, X.: Analysis and quantification of the diversities of aerosol life cycles within AeroCom, Atmos. Chem. Phys., 6, 1777-1813, doi:10.5194/acp6-1777-2006, 2006.

Tinsley, B. A., Rohrbaugh, R. P., Hei, M., and Beard, K. V.: Effects of image charges on scavenging of aerosol particles by cloud droplets and on droplet charging and possible ice nucleation processes, J. Atmos. Sci., 57, 2118-2134, 2000.

Tost, H., Jöckel, P., Kerkweg, A., Sander, R., and Lelieveld, J.: Technical note: A new comprehensive SCAVenging submodel for global atmospheric chemistry modelling, Atmos. Chem. Phys., 6, 565-574, doi:10.5194/acp-6-565-2006, 2006.

Tripathi, S. N. and Harrison, R. G.: Scavenging of electrified radioactive aerosol, Atmos. Environ., 35, 5817-5821, 2001.

Ulbrich, C. W.: Natural variations in the analytical form of the rain drop size distribution, J. Clim. Appl. Meteorol., 22, 1764-1775, 1983.

Vohl, O., Mitra, S. K., Diehl, K., Huber, G., Wurzler, S. C., Kratz K.-L., and Pruppacher, H. R.: A wind tunnel study of turbulence effects on the scavenging of aerosol particles by water drops, J. Atmos. Sci., 58, 3064-3072, 2001.

Volken, M. and Schumann, T.: A critical review of below-cloud aerosol scavenging results on Mt. Rigi, Water Air Soil Poll., 68, 15-28, 1993.

Waldvogel, A.: The $\mathrm{N}_{0}$ jump of raindrop spectra, J. Atmos. Sci., 31, 1067-1078, 1974.

Wang, P. K. and Pruppacher, H. R.: An experimental determination of the efficiency with which aerosol particles are collected by water drops in subsaturated air, J. Atmos. Sci., 34, 1664-1669, 1977.

Wang, P. K., Grover, S. N., and Pruppacher, H. R.: On the effect of electric charges on the scavenging of aerosol particles by clouds and small raindrops, J. Atmos. Sci., 35, 1735-1743, 1978.

Willis, P. T.: Functional fits to some observed drop size distributions and parameterization of rain, J. Atmos. Sci., 41(9), 1648-1661, 1984.

Young, K. C.: Microphysical processes in clouds, Oxford University Press, New York, USA, 427 pp., 1993.

Zhang, G., Xue, M., Cao, Q., and Dawson, D.: Diagnosing the intercept parameter for exponential raindrop size distribution based on video disdrometer observations: Model development, J. Appl. Meteor. Clim., 47, 2983-2992, 2008.

Zhang, L., Michelangeli, D. V., and Taylor, P. A.: Numerical studies of aerosol scavenging in low-level, warm stratiform clouds and precipitation, Atmos. Environ., 38, 4653-4665, 2004.

Zhang, L. and Vet, R.: A review of current knowledge concerning size-dependent aerosol removal, China Particuology, 4, 272-282, 2006. 